\title{
Theoretical Studies of Steric Effects on Intraligand Electron Delocalization: Implications for the Temporal Evolution of MLCT Excited States
}

\author{
Niels H. Damrauer, Brandon T. Weldon, and James K. McCusker* \\ Department of Chemistry, University of California at Berkeley, Berkeley, California 94720-1460
}

Received: December 11, 1997

\begin{abstract}
The effect of steric bulk on electron delocalization in 4-arylpyridines has been studied by computational methods. Ab initio (HF, UHF, ROHF, MP2, UMP2, and ROMP2) as well as density functional theory (USVWN and UB-LYP) approaches were applied to a series of molecules and their corresponding anions. These molecules are put forth as models for the ground and MLCT excited states of three polypyridyl ligands that were the subject of a recent report on the effects of sterics and delocalization on the photophysics of several $\mathrm{Ru}^{\mathrm{II}}$ complexes (Damrauer, et al. J. Am. Chem. Soc. 1997, 119, 8253). The present study finds that, in the series 4-phenylpyridine, 4-(o-tolyl)pyridine, and 4-(2,6-dimethylphenyl)pyridine, the steric effect of the ortho-methyl groups serves to increase the dihedral angle between the pyridyl and phenyl rings of the neutral compounds from ca. $45^{\circ}$ in the case of 4-phenylpyridine to ca. $65^{\circ}$ and $90^{\circ}$ in the mono- and dimethylated compounds, respectively. These results are generally consistent with the single-crystal X-ray structures of the three corresponding bipyridines, also reported herein. Upon one-electron reduction, calculations on all three model ligands reveal a preference for a coplanar structure, with the optimized geometries reflecting a balance between an energetic stabilization gained via conjugation in the planar form and unfavorable steric interactions between the methyl group(s) of the 4-aryl substituent and the pyridyl protons ortho to the central $\mathrm{C}-\mathrm{C}$ bond. Calculated dihedral angles were $0^{\circ}, \sim 25^{\circ}$, and $\sim 45^{\circ}$ for 4-phenyl-, 4-(o-tolyl)-, and 4-(2,6dimethyl)pyridine, respectively. Finally, a simulation of the Franck-Condon state evolution of MLCT states of molecules containing the bipyridyl analogues of the three models was carried out by computing singlepoint energies of each compound as its monoanion in the optimized neutral geometry. Comparison of these energies with those of the fully optimized anions revealed effective reorganization energies of $4-7 \mathrm{kcal} / \mathrm{mol}$ for 4-phenylpyridine, 4-7 kcal/mol for 4-(o-tolyl)pyridine, and ca. $6 \mathrm{kcal} / \mathrm{mol}$ for 4-(2,6-dimethylphenyl)pyridine. The implications of these results as they pertain to ultrafast spectroscopic studies of MLCT excitedstate evolution in the corresponding $\mathrm{Ru}^{\mathrm{II}}$ bipyridyl complexes are discussed.
\end{abstract}

\section{Introduction}

Metal complexes that exhibit metal-to-ligand charge transfer (MLCT) transitions represent an important class of molecules in the inorganic photophysical and photochemical communities. ${ }^{1}$ In addition to fundamental studies of electronic structure, such metal complexes can serve as templates for electron injection into proteins for the study of biological electron-transfer dynamics $^{2}$ as well as chromophores in molecular and semiconductor assemblies for solar energy conversion. ${ }^{3}$ For the general case of a metal-ligand $(\mathrm{M}-\mathrm{L})$ chromophore, excitation in the region of a MLCT absorption results in formal oxidation of the metal center and reduction of the ligand (eq 1).

$$
\left[\mathrm{M}^{\mathrm{II}}(\mathrm{L})_{3}\right]^{2+} \stackrel{(h v)}{\longrightarrow}\left[\mathrm{M}^{\mathrm{III}}\left(\mathrm{L}^{-}\right)(\mathrm{L})_{2}\right]^{2+}
$$

Typically, the electron is transferred from what is nominally a metal-based $d$ orbital to an antibonding $\left(\pi^{*}\right)$ orbital of the ligand. As a result, the electronic structure of the ligand(s) plays a crucial role in establishing the photophysical properties of the molecule as a whole.

Traditionally, research efforts geared toward tuning excitedstate properties of metal complexes have focused on the manipulation of the energetics of the lowest energy MLCT excited states. Such changes can be achieved quite easily through synthetic modifications of the ligands that influence either the basicity of the ligand or the energetics of the acceptor orbitals. ${ }^{4}$ For a large class of polypyridyl complexes of $\mathrm{Ru}^{\mathrm{II}}$, Os ${ }^{\mathrm{II}}$, and $\mathrm{Re}^{\mathrm{I}}$, the mechanism by which MLCT excited states are influenced by such energetics is described by the energy gap law. ${ }^{5}$ This model, which closely resembles the multiphonon nonadiabatic descriptions of electron-transfer developed by Bixon, Jortner, and others ${ }^{6}$ describes a nonradiative transition in terms of a coupling of vibronic states on an initial potential energy surface to isoenergetic levels of the final state. Thus, ligand energetics affect MLCT excited-state properties by influencing the degree of vibronic coupling between the excitedand ground-state surfaces. We have recently published a study ${ }^{7}$ where MLCT excited-state properties of a series of 4,4'-arylsubstituted bipyridine complexes of ruthenium were tuned via a second mechanism also described by the energy gap law but less frequently discussed in the literature. In this mechanism, the degree of nonradiative coupling is modulated through changes in the relative displacement of excited- and groundstate potential energy surfaces along a nuclear coordinate relevant for nonradiative decay. We have shown that rates of radiative and nonradiative relaxation are strongly dependent on the degree to which a transferred electron can delocalize within the $\pi$ system of an acceptor ligand, a property that we refer to as intraligand delocalization. 
This paper presents a theoretical treatment of steric effects on ligand geometry: specifically, how these effects influence the degree of electron delocalization within the ligand. Ab initio calculations (HF and MP2) were undertaken in the study of neutral aryl-pyridines as models for ground-state ligand structure, while ab initio (UHF, UMP2, ROHF, and ROMP2) and density functional calculations (UB-LYP and USVWN) were used to study reduced aryl-pyridines as models for MLCT excited states. In addition, we report X-ray crystal structures for the neutral ligands used in the previously mentioned study (4,4'-diphenyl-2,2'-bipyridine, 4,4'-di-o-tolyl-2,2'-bipyridine, and 4,4'-dimesityl-2,2'-bipyridine) and compare these solid-state structures with their calculational models. Finally, we consider the energetic and structural driving forces within the ligand associated with the evolution of the MLCT Franck-Condon state to its vibronically relaxed configuration. These observations are discussed with regard to ultrafast studies of excitedstate evolution and the prospects of time-resolving delocalization effects in these types of complexes.

\section{Experimental Section}

Calculations of Neutral Species. Ab initio calculations were carried out using the Gaussian 92 suite of programs ${ }^{8}$ for 4-phenylpyridine and the Gaussian 94 suite of programs ${ }^{9}$ for 4-(o-tolyl)pyridine and 4-(2,6-dimethylphenyl)pyridine. For the three molecules, ground-state geometries were optimized and energies calculated using restricted Hartree-Fock (RHF) methods employing 3-21G(d) and 6-31G(d) basis sets as well as second-order perturbation theory (MP2) ${ }^{10}$ employing the 6-31G(d) basis set. In addition, using the above methods and basis sets, the geometries and energies of the torsional (inter-ring torsion angle $\theta$ ) transition states were calculated. Twist angles are measured between two carbon atoms adjacent to the central 4,7 carbon-carbon bond, i.e., for 4-phenylpyridine,

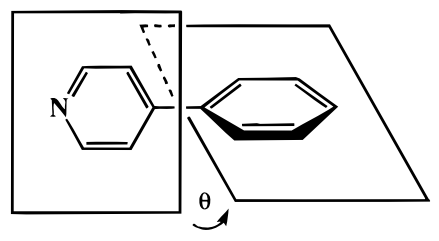

For each RHF stationary point, the analytic Hessian was calculated and diagonalized to determine if the structures are stationary minima or transition states. Stationary minima showed only positive definite vibrational modes, while transition states showed one vibrational mode with an imaginary frequency. In the case of the torsional transition state of 4-(2,6dimethylphenyl)pyridine, two imaginary frequencies were seen, which is discussed further in the Results and Discussion section. Details of calculations specific to each molecule are described below.

The molecular geometry of 4-phenylpyridine was fully optimized with RHF as well as MP2 methods. The only geometric constraint was that the molecule was forced to maintain $C_{2}$ symmetry. In addition, the energies and geometries of the two torsional transition states corresponding to coplanar ring systems $\left(C_{2 v}, \theta=0^{\circ}\right)$ and perpendicular ring systems $\left(C_{2 v}\right.$, $\theta=90^{\circ}$ ) were calculated with RHF and MP2 methods. For these transition-state calculations, only the dihedral angle was restrained, while all other geometrical properties were allowed to fully optimize.

The molecular geometry of 4-(o-tolyl)pyridine was fully optimized with RHF and MP2 methods with no constraints on the geometry, i.e., $C_{1}$ symmetry. For the RHF/3-21G(d) calculation, the lowest energy structure is one in which $\theta=$ $90^{\circ}$, and consequently, there is only one calculated torsional transition state through $\theta=0^{\circ}$. This structure was fully optimized within the imposed $C_{\mathrm{s}}$ symmetry. For RHF/6-31G(d) and MP2/6-31G(d) calculations, the optimized structure is one in which the dihedral angle $\theta$ lies between $0^{\circ}$ and $90^{\circ}$, and thus, there are two torsional transition states corresponding to coplanar ring systems $\left(C_{s}, \theta=0^{\circ}\right)$ and perpendicular ring systems $\left(C_{s}, \theta=90^{\circ}\right)$. These transition states were fully optimized with constraints only on the central dihedral angle. For all transition states, the rotational orientation of the methyl group hydrogen atoms was optimized within the imposed $C_{s}$ symmetry.

The molecular geometry of 4-(2,6-dimethylphenyl)pyridine was fully optimized with RHF and MP2 methods. The only geometric constraint was that the molecule was forced to maintain $C_{2}$ symmetry. The lowest energy structure for each method is one in which $\theta=90^{\circ}$. The energy and geometry of the $\theta=0^{\circ}$ transition state $\left(C_{2 v}\right)$ was calculated for each of the method/basis-set combinations with the rotational orientation of the methyl group hydrogens being optimized within the imposed $C_{2 v}$ geometry.

Calculations of Anionic Species. Using the Gaussian 94 suite of programs, ${ }^{9}$ the energies and geometries of [4-phenyl-

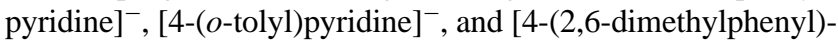
pyridine $]^{-}$were calculated and optimized with Hartree-Fock, density functional theory (DFT), and in some cases secondorder perturbation theory (MP2) methods. The Hartree-Fock calculations included unrestricted Hartree-Fock (UHF) as well as restricted open-shell Hartree-Fock (ROHF). The unrestricted DFT calculations were done with two variations, S-VWN and B-LYP. The first of these combines the Slater exchange functional $(\mathrm{S})$ with the local spin density functional of Vosko, Wilk, and Nusair (VWN). ${ }^{11}$ The second of these combines the gradient-corrected Becke exchange (B) with the nonlocal spin density functional of Lee, Yang, and Parr (LYP). ${ }^{12}$ The 3-21G(d), 3-21+G(d), 6-31G(d), and 6-31+G(d) basis sets were used for all methods and molecules. Geometry optimizations of [4-phenylpyridine $]^{-}$and [4-(2,6-dimethylphenyl)pyridine ${ }^{-}$were done within the constraints of $C_{2}$ symmetry with no other restrictions on the molecular geometry. Geometry optimizations of [4-(o-tolyl)pyridine ${ }^{-}$were done with no symmetry constraints. For all stationary points found with UHF methods, excluding the UHF/6-31+G(d) calculations of [4-(o-tolyl)pyridine $]^{-}$and [4-(2,6-dimethylphenyl)pyridine $]^{-}$, the analytic Hessian was calculated and diagonalized. These calculations showed only positive definite modes, indicating that these structures are indeed stationary minima. The analytic Hessian was not calculated and diagonalized for all methods because of the computational cost but does not appear to be necessary.

The energy of Franck-Condon-state relaxation $\left(\Delta E_{\theta}\right)$ was estimated for the three molecular anions using the abovementioned basis-sets and open-shell methods. In addition, restricted open-shell MP2 (ROMP2) methods were applied, especially in the case of [4-(2,6-dimethylphenyl)pyridine $]^{-}$. The energy of relaxation $\left(\Delta E_{\theta}\right)$ was determined as the difference in energy between the reduced ligand fixed in the geometry of the neutral (the Franck-Condon state) and the reduced ligand fixed in a fully relaxed geometry. The frozen molecular geometry used to calculate the Franck-Condon state for these anions was taken from the MP2/6-31G(d) ground-state optimized geometries of the corresponding neutrals. The molecular geometry used to describe the fully relaxed species was also 
TABLE 1: Crystallographic Data for 4,4' -Diphenyl-2, $2^{\prime}$ bipyridine (dpb), 4,4'-Di-o-tolyl-2,2'-bipyridine (dotb), and 4,4'-Dimesityl-2,2'-bipyridine (dmesb)

\begin{tabular}{|c|c|c|c|}
\hline & $\mathrm{dpb}$ & dotb & dmesb \\
\hline empirical formula & $\mathrm{C}_{22} \mathrm{H}_{16} \mathrm{~N}_{2}$ & $\mathrm{C}_{24} \mathrm{H}_{20} \mathrm{~N}_{2}$ & $\mathrm{C}_{28} \mathrm{H}_{28} \mathrm{~N}_{2}$ \\
\hline formula weight & 308.44 & 336.44 & 392.23 \\
\hline crystal color, habit & $\begin{array}{l}\text { colorless, } \\
\text { needles }\end{array}$ & $\begin{array}{l}\text { colorless, } \\
\text { polyhedron }\end{array}$ & $\begin{array}{l}\text { colorless, } \\
\text { polyhedron }\end{array}$ \\
\hline crystal system & monoclinic & monoclinic & monoclinic \\
\hline space group & $P 2_{1} / a(\# 14)$ & $P 2{ }_{1} / c(\# 14)$ & $P 2_{1} / n(\# 14)$ \\
\hline temp $\left({ }^{\circ} \mathrm{C}\right)$ & -117 & -134 & -139 \\
\hline \multicolumn{4}{|l|}{ cell dimensions } \\
\hline$a(\AA)$ & $7.54860(10)$ & $7.0638(9)$ & $9.9996(7)$ \\
\hline$b(\AA)$ & 11.43 & $11.0932(3)$ & $9.2771(6)$ \\
\hline$c(\AA)$ & $9.2950(3)$ & $11.3030(4)$ & $12.4337(8)$ \\
\hline$\beta(\mathrm{deg})$ & $105.042(1)$ & 104.641(2) & $97.034(1)$ \\
\hline$V\left(\AA^{3}\right)$ & $775.05(3)$ & $856.94(3)$ & $1144.76(23)$ \\
\hline$Z$ & 2 & 2 & 2 \\
\hline goodness of fit $(S)^{a}$ & 1.89 & 2.66 & 2.42 \\
\hline$R^{b}$ & 0.036 & 0.034 & 0.041 \\
\hline$R_{\mathrm{w}}{ }^{\mathrm{c}}$ & 0.045 & 0.045 & 0.058 \\
\hline
\end{tabular}

frozen. For each of the anions, this geometry was determined with UMP2/6-31G(d) methods and corresponds to the lowest energy structure.

X-ray Structure Determinations. Single-crystal X-ray structure determinations of $4,4^{\prime}$-diphenyl-2,2' $2^{\prime}$-bipyridine (dpb), 4,4'-di-o-tolyl-2,2'-bipyridine (dotb), and 4,4'-di-mesityl-2,2' bipyridine (dmesb) were carried out in the CHEXRAY facility of the University of California, Berkeley. All measurements were made on a Siemens SMART diffractometer with graphite monochromated Mo $\mathrm{K} \alpha$ radiation. All calculations were performed with the teXsan crystallographic software package of the Molecular Structure Corporation. ${ }^{13}$

(a) 4,4'-Diphenyl-2,2'-bipyridine (dpb). Colorless crystals of 4,4'-diphenyl-2,2'-bipyridine were obtained by pentane diffusion into an ethanol solution. One crystal having approximate dimensions of $0.20 \times 0.25 \times 0.12 \mathrm{~mm}$ was mounted on a glass fiber with Paratone $\mathrm{N}$ hydrocarbon oil. Crystallographic data are summarized in Table 1. Cell constants and an orientation matrix obtained from a least-squares refinement using the measured positions of 2632 reflections with $I>10 \sigma$ in the range $3.00^{\circ}<2 \theta<45.00^{\circ}$ corresponded to a primitive monoclinic cell. The systematic absences of $h 0 l(h \neq 2 n)$ and $0 k 0(k \neq$ $2 n$ ) uniquely determined the space group to be $P 2_{1} / a$ (\#14). Data were integrated to a maximum $2 \theta$ value of $51.9^{\circ}$. The data were corrected for Lorentz and polarization effects. A secondary extinction correction was also applied. No decay correction or absorption correction was applied. The 3689 integrated and corrected reflections were averaged to yield 1443 unique data $\left(R_{\text {int }}=0.027\right)$. The structure was solved by direct methods and expanded using Fourier techniques. All non-hydrogen atoms were refined anisotropically. Hydrogen atoms were included at calculated positions but not refined. The final cycle of fullmatrix least-squares refinement was based on 1032 observed reflections $(I>3.00 \sigma(I))$ and 142 variable parameters and converged with unweighted and weighted agreement factors of $R=0.036$ and $R_{\mathrm{w}}=0.045$, respectively. The weighting scheme was based on counting statistics and included a factor $(p=$ 0.003 ) to downweight the intense reflections. The maximum and minimum peaks on the final difference Fourier map corresponded to 0.20 and $-0.14 \mathrm{e}^{-} / \AA^{3}$, respectively.

(b) 4,4'-Di-o-tolyl-2,2'-bipyridine (dotb). Colorless crystals of 4,4'-di-o-tolyl-2,2'-bipyridine were obtained by slow evaporation of a tetrahydrofuran solution. One crystal having ap- proximate dimensions of $0.55 \times 0.21 \times 0.15 \mathrm{~mm}$ was mounted on a glass fiber with Paratone $\mathrm{N}$ hydrocarbon oil. Crystallographic data are summarized in Table 1. Cell constants and an orientation matrix obtained from a least-squares refinement using the measured positions of 3205 reflections with $I>10 \sigma$ in the range $3.00^{\circ}<2 \theta<45.00^{\circ}$ corresponded to a primitive monoclinic cell. The systematic absences of $h 0 l(l \neq 2 n)$ and $0 k 0(k \neq 2 n)$ uniquely determined the space group to be $P 2_{1} / c$ (\#14). Data were integrated to a maximum $2 \theta$ value of $52.2^{\circ}$. The data were corrected for Lorentz and polarization effects. No decay or empirical absorption corrections were applied. The 3838 integrated and corrected reflections were averaged to yield 1582 unique data $\left(R_{\text {int }}=0.019\right)$. The structure was solved by direct methods and expanded using Fourier techniques. All nonhydrogen atoms were refined anisotropically. Hydrogen atoms were included at calculated positions but not refined. The final cycle of full-matrix least-squares refinement was based on 1300 observed reflections $(I>3.00 \sigma(I))$ and 118 variable parameters and converged with unweighted and weighted agreement factors of $R=0.034$ and $R_{\mathrm{w}}=0.045$, respectively. The weighting scheme was based on counting statistics and included a factor $(p=0.003)$ to downweight the intense reflections. The maximum and minimum peaks on the final difference Fourier map corresponded to 0.17 and $-0.19 \mathrm{e}^{-} / \AA^{3}$, respectively.

(c) 4,4'-Di-mesityl-2,2' -bipyridine (dmesb). Colorless crystals of 4,4'-di-mesityl-2,2'-bipyridine were obtained by slow evaporation of a tetrahydrofuran solution. One crystal having the approximate dimensions of $0.50 \times 0.45 \times 0.45 \mathrm{~mm}$ was mounted on a glass fiber with Paratone $\mathrm{N}$ hydrocarbon oil. Crystallographic data are summarized in Table 1. Cell constants and an orientation matrix obtained from a least-squares refinement using the measured positions of 4238 reflections with $I$ $>10 \sigma$ in the range $3.00^{\circ}<2 \theta<45.00^{\circ}$ corresponded to a primitive monoclinic cell. The systematic absences of $h 0 l(h$ $+l \neq 2 n)$ and $0 k 0(k \neq 2 n)$ uniquely determined the space group to be $P 2_{1} / n$ (\#14). Data were integrated to a maximum $2 \theta$ value of $51.9^{\circ}$. The data were corrected for Lorentz and polarization effects. No decay or empirical absorption corrections were applied. The 5482 integrated and corrected reflections were averaged to yield 2141 unique data $\left(R_{\text {int }}=0.032\right)$. The structure was solved by direct methods and expanded by using Fourier techniques. All non-hydrogen atoms were refined anisotropically. Hydrogen atoms were included at calculated positions but not refined. The final cycle of full-matrix leastsquares refinement was based on 1651 observed reflections ( $I$ $>3.00 \sigma(I))$ and 192 variable parameters and converged with unweighted and weighted agreement factors of $R=0.041$ and $R_{\mathrm{w}}=0.058$, respectively. The weighting scheme was based on counting statistics and included a factor $(p=0.030)$ to downweight the intense reflections. The maximum and minimum peaks on the final difference Fourier map corresponded to 0.24 and $-0.17 \mathrm{e}^{-/ \AA^{3}}$, respectively.

\section{Results and Discussion}

I. Background Discussion of $\left[\mathrm{Ru}(\mathrm{dpb})_{3}\right]\left(\mathrm{PF}_{6}\right)_{2}$ and dpb Series: Basis for Theoretical Model. There have been several accounts in the literature in which the concept of intraligand delocalization has been used to explain photophysical properties of metal complexes. For example, Phifer and McMillin applied this idea to rationalize aryl substituent effects on charge-transfer absorption intensities in phenanthroline complexes of $\mathrm{Cu}^{\mathrm{I}}$. ${ }^{14 \mathrm{a}}$ Strouse et al. ${ }^{14 \mathrm{~b}}$ have rationalized the unusually long excitedstate lifetime of $\left[(\mathrm{dmb})_{2} \operatorname{Ru}(\mu \text {-bbpe }) \mathrm{Ru}(\mathrm{dmb})_{2}\right]^{4+}$ (where bbpe 
is trans-1,2-bis(4-(4'-methyl)-2,2'-bipyridyl)ethene by postulating that electron delocalization within the bridging bbpe ligand results in a small horizontal displacement between ground- and excited-state potential energy surfaces (PES) and thus a reduction of vibronic coupling between the two states. More recent work by Sauvage and co-workers has also examined the effect of delocalization in bimetallic complexes. ${ }^{14 \mathrm{c}}$ Finally, Treadway et al. ${ }^{15}$ have analyzed a number of MLCT systems from the literature concerning the effects of delocalization and acceptor ligand rigidity on decreasing rates of nonradiative excited-state decay. As was alluded to above, we have recently detailed the photophysics of $\left[\mathrm{Ru}(\mathrm{dpb})_{3}\right]\left(\mathrm{PF}_{6}\right)_{2}$ and related compounds in the context of intraligand delocalization. ${ }^{7}$ Synthetic manipulations of ligand structure provided compelling evidence that the photophysical properties of these compounds are dictated to a large extent by intraligand delocalization in the ${ }^{3}$ MLCT excited state. The ligands, comprising what we refer to as the "dpb series", are illustrated below.

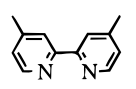

(dmb)

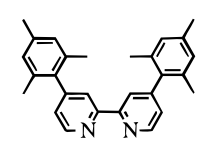

(dmesb)

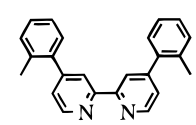

(dotb)

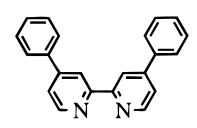

(dpb)
Based on a model that places the 4 and $4^{\prime}$ phenyl rings of dpb coplanar with the bipyridyl fragment in the ligand's photoreduced state, the dpb series is meant to offer a stepwise decrease (from dpb to dmb) in the amount of ligand-based delocalization that is energetically allowed in the ${ }^{3}$ MLCT excited state. That is, by introducing steric bulk, we are turning off the mechanism by which a reduced ligand $\left(\mathrm{L}^{-}\right.$in the excited state) can achieve planarity between the aryl substituents and the pyridine rings, a process necessary for extended delocalization of the electron in the $\pi^{*}$ system. Experimentally, we observed trends in photophysical data across the dpb series consistent with this model. For example, radiative quantum yields undergo a stepwise decrease: $\Phi_{\mathrm{em}}\left(\left[\mathrm{Ru}(\mathrm{dpb})_{3}\right]\left(\mathrm{PF}_{6}\right)_{2}\right)>\Phi_{\mathrm{em}}\left(\left[\mathrm{Ru}(\text { dotb })_{3}\right]-\right.$ $\left.\left(\mathrm{PF}_{6}\right)_{2}\right)>\Phi_{\mathrm{em}}\left(\left[\mathrm{Ru}(\mathrm{dmesb})_{3}\right]\left(\mathrm{PF}_{6}\right)_{2}\right)>\Phi_{\mathrm{em}}\left(\left[\mathrm{Ru}(\mathrm{dmb})_{3}\right]\left(\mathrm{PF}_{6}\right)_{2}\right)$. A similar decrease is seen in the intensity of the low-energy ${ }^{3}$ MLCT transient $\pi^{* \leftarrow} \pi^{*}$ ligand-based absorption, consistent with delocalization, wherein $\Delta A_{530 \mathrm{~nm}}\left(\left[\mathrm{Ru}(\mathrm{dpb})_{3}\right]\left(\mathrm{PF}_{6}\right)_{2}\right)>\Delta A_{530 \mathrm{~nm}^{-}}$ $\left(\left[\mathrm{Ru}(\text { dotb })_{3}\right]\left(\mathrm{PF}_{6}\right)_{2}\right)>\Delta A_{530 \mathrm{~nm}}\left(\left[\mathrm{Ru}\left(\right.\right.\right.$ dmesb $\left.\left._{3}\right]\left(\mathrm{PF}_{6}\right)_{2}\right)>\Delta A_{530 \mathrm{~nm}^{-}}$ $\left(\left[\mathrm{Ru}(\mathrm{dmb})_{3}\right]\left(\mathrm{PF}_{6}\right)_{2}\right)$.

It is well established in the literature that poly-aryl compounds such as biphenyl have nonplanar neutral geometries in the gas phase and in solution, while their reduced forms are planar and fully delocalized. For example, in the gas phase, the dihedral angle $\theta$ between the two rings of biphenyl is $\sim 44^{\circ}$ for the neutral compound and $0^{\circ}$ for the reduced form. ${ }^{16}$ A similar trend appears to hold true for the phenyl-pyridyl moieties within the dpb ligand. In the aforementioned paper, we reported the X-ray crystal structure of a metal complex containing the $\mathrm{dpb}$ ligand, namely, $\left[\mathrm{Ru}(\mathrm{dmb})_{2}(\mathrm{dpb})\right]\left(\mathrm{PF}_{6}\right)_{2}$. In this groundstate structure, the phenyl substituents lie canted with respect to the bipyridine $\left(\theta=28^{\circ} \pm 1^{\circ}\right)$. Initial ab initio calculations of 4-phenylpyridine, which serves as a model for ground-state ligand geometry, suggested that this angle $\theta$ is on the order of $45^{\circ}$ in the gas phase. The origin of this $90^{\circ}>\theta>0^{\circ}$ twist angle appears to be an energetic compromise between a planar delocalized ground state and steric repulsions between protons ortho to the phenyl-pyridyl bond.

While numerous pieces of spectroscopic data suggest a planar delocalized $(\mathrm{dpb})^{-}$in the ${ }^{3} \mathrm{MLCT}$ excited state of $\left[\mathrm{Ru}(\mathrm{dpb})_{3}\right]^{2+}$, we have no structural evidence (X-ray or NMR) to support this.
In addition, packing forces in crystals used for X-ray structural determination can influence the overall ligand geometry; this is especially true when potential surfaces are soft, as they are known to be with regard to phenyl-phenyl and phenyl-pyridyl twist angles. Therefore, we turned to a theoretical treatment of ligand structure in order to gain more insight into the effect of sterics and ligand geometry on intraligand electron delocalization. Ab initio and density functional theory calculations of model ligand geometries provide a means of estimating groundstate ligand twist angles as well as the degree of planarity/ delocalization in the reduced-ligand excited states of these metal complexes. In addition, we can use aspects of these calculations to estimate the thermodynamic driving force associated with relaxation from a canted Franck-Condon state to a more coplanar thermalized excited state in anticipation of ultrafast studies of excited-state evolution in the parent metal complexes (vide infra).

In our computational treatment, we have studied isolated model ligands rather than the full $\left[\mathrm{Ru}(\mathrm{L})_{3}\right]^{2+}$ metal complexes. This involves some significant approximations. The first is that, although the metal perturbs the overall electronic structure of the ligand, we suggest that metal-ligand interactions in the ground state are not significantly different than those in the excited state. The majority of the $\mathrm{M}-\mathrm{L}$ interaction (i.e., the $\mathrm{Ru}-\mathrm{N}$ bonds) in the ground and excited state is $\sigma$ in nature, whereas we are primarily interested in intraligand delocalization as it pertains to the $\pi$ system of the ligand. The second approximation concerns the size of the ligand itself. Rather than computationally treating aryl-substituted bipyridines, we have used 4-arylpyridines to model the ground-state ligand geometries and reduced 4-arylpyridines to describe MLCT excited-state ligand geometries. The model ligands used in this study are shown below next to the corresponding metalcomplex ligands.

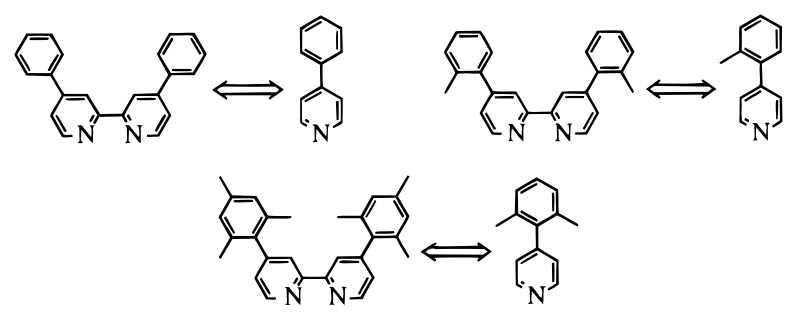

Thus, the ligand dpb is modeled by 4-phenylpyridine, dotb by 4-(o-tolyl)pyridine, and dmesb by 4-(2,6-dimethylphenyl)pyridine. We believe that in these smaller systems, the arylpyridine $\pi$ interactions should be indicative of those taking place in the actual ligands. Finally, we must discuss the theoretical treatment of the MLCT process itself. In the ground state of these metal complexes, $\mathrm{Ru}-\mathrm{N}$ interactions that are $\pi$ in nature are generally discussed in the context of $\pi$-back-bonding from metal $\mathrm{d}(\pi)$ orbitals into the $\pi^{*}$ system of the ligand. To the extent this takes place, it may be most appropriate to treat ground-state ligands as having partially reduced $\pi^{*}$ systems. Ignoring crystal packing forces, this is one possible explanation for the $\theta=28^{\circ}$ (i.e., $<45^{\circ}$ ) twist angles seen in the structure of $\left[\mathrm{Ru}(\mathrm{dmb})_{2}(\mathrm{dpb})\right]\left(\mathrm{PF}_{6}\right)_{2}$ (vide supra). The same can be said of ligand-metal $\pi$ interactions in the ${ }^{3}$ MLCT excited state. In our computational model, a unit electron is used to reduce the ligand, again implying isolation from the metal. While this is not an exact theoretical treatment, it nonetheless brackets the actual $\pi$ interactions taking place in the metal complexes. These approximations afford us a more computationally feasible 
TABLE 2: Ab Initio Calculations on Neutral 4-Phenylpyridine

\begin{tabular}{|c|c|c|c|c|c|c|}
\hline \multirow[b]{2}{*}{ method/basis set } & \multicolumn{2}{|c|}{ optimized structure } & \multicolumn{2}{|c|}{ transition-state structure $\left(\theta^{b}=0^{\circ}\right)$} & \multicolumn{2}{|c|}{ transition-state structure $\left(\theta^{b}=90^{\circ}\right)$} \\
\hline & $\begin{array}{c}\text { energy (hartrees) } \\
\text { (NIMAG) }^{a}\end{array}$ & $\begin{array}{l}\text { geometrical } \\
\text { properties }\end{array}$ & $\begin{array}{c}\Delta E_{0^{d}}{ }^{d} \\
(\mathrm{NIMAG})^{a}\end{array}$ & $\begin{array}{l}\text { geometrical } \\
\text { properties }\end{array}$ & $\begin{array}{c}\Delta E_{90^{d}} \\
(\mathrm{NIMAG})^{a}\end{array}$ & $\begin{array}{l}\text { geometrical } \\
\text { properties }\end{array}$ \\
\hline $\mathrm{RHF} / 3-21 \mathrm{G}(\mathrm{d})$ & $\begin{array}{l}-473.581779 \\
(0)\end{array}$ & $\begin{array}{l}\theta^{b}=50.1^{\circ} \\
\mathrm{C}-\mathrm{C}^{c}=1.488 \AA\end{array}$ & $\begin{array}{l}3.29 \mathrm{kca} / \mathrm{mol} \\
\text { (1) }\end{array}$ & $\mathrm{C}-\mathrm{C}^{c}=1.499 \AA$ & $\begin{array}{l}0.911 \mathrm{kcal} / \mathrm{mol} \\
\text { (1) }\end{array}$ & $\mathrm{C}-\mathrm{C}^{c}=1.493 \AA$ \\
\hline RHF/6-31G(d) & $\begin{array}{l}-476.247477 \\
\text { (0) }\end{array}$ & $\begin{array}{l}\theta^{b}=44.3^{\circ} \\
\mathrm{C}-\mathrm{C}^{c}=1.490 \AA\end{array}$ & $\begin{array}{l}2.67 \mathrm{kcal} / \mathrm{mol} \\
\text { (1) }\end{array}$ & $\mathrm{C}-\mathrm{C}^{c}=1.498 \AA$ & $\begin{array}{l}1.62 \mathrm{kcal} / \mathrm{mol} \\
\text { (1) }\end{array}$ & $\mathrm{C}-\mathrm{C}^{c}=1.496 \AA$ \\
\hline MP2/6-31G(d) & -477.793958 & $\begin{array}{l}\theta^{b}=44.6^{\circ} \\
\mathrm{C}-\mathrm{C}^{c}=1.477 \AA\end{array}$ & $3.31 \mathrm{kcal} / \mathrm{mol}$ & $\mathrm{C}-\mathrm{C}^{c}=1.488 \AA$ & $1.80 \mathrm{kcal} / \mathrm{mol}$ & $\mathrm{C}-\mathrm{C}^{c}=1.483 \AA$ \\
\hline
\end{tabular}

${ }^{a}$ NIMAG $=$ number of imaginary frequencies. ${ }^{b} \theta$ refers to the twist angle between the aryl and pyridyl rings. ${ }^{c} \mathrm{C}-\mathrm{C}$ refers to the carboncarbon bond distance between the aryl and pyridyl rings. ${ }^{d} \Delta E$ refers to the energetic cost of achieving the transition-state structure from the optimized structure.

TABLE 3: Ab Initio Calculations on Neutral 4-(o-Tolyl)pyridine

\begin{tabular}{|c|c|c|c|c|c|c|}
\hline \multirow[b]{2}{*}{ method/basis set } & \multicolumn{2}{|c|}{ optimized structure } & \multicolumn{2}{|c|}{ transition-state structure $\left(\theta^{b}=0^{\circ}\right)$} & \multicolumn{2}{|c|}{ transition-state structure $\left(\theta^{b}=90^{\circ}\right)$} \\
\hline & $\begin{array}{l}\text { energy (hartrees) } \\
\text { (NIMAG) })^{a}\end{array}$ & $\begin{array}{l}\text { geometrical } \\
\text { properties }\end{array}$ & $\begin{array}{c}\Delta E_{0^{d}}{ }^{d} \\
(\mathrm{NIMAG})^{a}\end{array}$ & $\begin{array}{l}\text { geometrical } \\
\text { properties }\end{array}$ & $\begin{array}{c}\Delta E_{90^{d}} \\
(\mathrm{NIMAG})^{a}\end{array}$ & $\begin{array}{l}\text { geometrical } \\
\text { properties }\end{array}$ \\
\hline RHF/3-21G(d) & $\begin{array}{l}-512.400507 \\
(0)\end{array}$ & $\begin{array}{l}\theta^{b}=90^{\circ} \\
\mathrm{C}-\mathrm{C}^{c}=1.495 \AA\end{array}$ & $\begin{array}{l}10.5 \mathrm{kcal} / \mathrm{mol} \\
\text { (1) }\end{array}$ & $\mathrm{C}-\mathrm{C}^{c}=1.514 \AA$ & & \\
\hline RHF/6-31G(d) & $\begin{array}{l}-515.280745 \\
(0)\end{array}$ & $\begin{array}{l}\theta^{b}=66.5^{\circ}(\mathrm{av}) \\
\mathrm{C}-\mathrm{C}^{c}=1.496 \AA\end{array}$ & $\begin{array}{l}8.62 \mathrm{kcal} / \mathrm{mol} \\
\text { (1) }\end{array}$ & $\mathrm{C}-\mathrm{C}^{c}=1.511 \AA$ & $\begin{array}{l}0.118 \mathrm{kcal} / \mathrm{mol} \\
\text { (1) }\end{array}$ & $\mathrm{C}-\mathrm{C}^{c}=1.498 \AA$ \\
\hline $\mathrm{MP} 2 / 6-31 \mathrm{G}(\mathrm{d})$ & -516.963445 & $\begin{array}{l}\theta^{b}=59.6^{\circ}(\mathrm{av}) \\
\mathrm{C}-\mathrm{C}^{c}=1.481 \AA\end{array}$ & $8.98 \mathrm{kcal} / \mathrm{mol}$ & $\mathrm{C}-\mathrm{C}^{c}=1.500 \AA$ & $0.327 \mathrm{kcal} / \mathrm{mol}$ & $\mathrm{C}-\mathrm{C}^{c}=1.484 \AA$ \\
\hline
\end{tabular}

${ }^{a} \mathrm{NIMAG}=$ number of imaginary frequencies. ${ }^{b} \theta$ refers to the twist angle between the aryl and pyridyl rings. ${ }^{c} \mathrm{C}-\mathrm{C}$ refers to the carbon carbon bond distance between the aryl and pyridyl rings. ${ }^{d} \Delta E$ refers to the energetic cost of achieving the transition-state structure from the optimized structure.

problem, one in which we can use extensive basis sets to create the relevant ligand molecular orbitals.

II. Ground-State Neutral Calculations: Establishment of Twist Angle $\boldsymbol{\theta}$ and Barriers to Rotation. As was alluded to above, considerable effort has been spent on the theoretical and experimental treatment of biphenyl. Recent work by Karpfen et al. predicts a twist angle $(\theta)$ between the two ring systems of $46^{\circ}$ using MP2 methods. ${ }^{17 a}$ Also recently, Rubio et al. have published a CASSCF/DZP study of neutral biphenyl where they report the twist angle $(\theta)$ between the two ring systems of the biphenyl to be $44.34^{\circ} .{ }^{18}$ This result is in relatively close agreement with an earlier theoretical treatment by Tsuzuki et al., who report $\theta=46.26^{\circ}$ using Hartree-Fock theory and a 6-31G(p,d) basis set. ${ }^{19}$ Electron diffraction techniques were used by Almenningen et al. to determine the gas-phase structure of biphenyl and suggest a twist angle of $44.4^{\circ},{ }^{16}$ in good agreement with the calculations. We have used restricted Hartree-Fock methods and second-order perturbation theory to determine geometries of the aforementioned model ligands in order to ascertain how the twist angle $\theta$ changes as steric bulk is introduced at ortho positions of the aryl group. This angle reflects how the degree of ground-state aryl-pyridyl delocalization changes with added hindrances to planarity. Table 2 lists energetic and structural properties for neutral 4-phenylpyridine. For the three method/basis-set combinations used, the lowest energy structure is twisted. The geometry optimization with the smallest basis set $(\mathrm{RHF} / 3-21 \mathrm{G}(\mathrm{d}))$ may have overestimated the twist angle at $\theta=50.1^{\circ}$; however, both calculations with the $6-31 \mathrm{G}(\mathrm{d})$ basis set are in close agreement with each other $\left(\theta=44.3^{\circ}, 44.6^{\circ}\right)$. We note the similarity between the calculated twist angle(s) of 4-phenylpyridine and those discussed above for biphenyl. Frequency calculations show that there are zero imaginary frequencies for the canted 4-phenylpyridine structures, indicating that these are indeed stationary minima. By symmetry, the coplanar $\left(\theta=0^{\circ}\right)$ and the perpendicular $\left(\theta=90^{\circ}\right)$ structures are rotational transition states. This is confirmed with frequency calculations where the number of imaginary frequencies for these geometries is one. The energetic cost of going through these states is given by $\Delta E_{0^{\circ}}$ and $\Delta E_{90^{\circ}}$, respectively. At $\theta=90^{\circ}$ unfavorable steric interactions are at a minimum, and any stabilization due to delocalization is turned off due to orthogonality of the phenyl and pyridyl $\pi$ systems. At $\theta=0^{\circ}$ the opposite is true, and the stabilization due to delocalization is at a maximum, as is destabilization due to steric interactions. It should be noted that the minimum structure on this potential energy surface is determined by a convolution of energetically stabilizing delocalization (manifested as a negative contribution to the calculated energy) and energetically destabilizing sterics (positive contribution). It is therefore difficult to assign absolute energetic contributions at the two rotational transition states since the overall energy reflects a sum of these two opposing terms. We can, however, view the calculated values as effective lower limits at each transition state. Thus, the component of $\Delta E_{0^{\circ}}$ due to sterics is $>3.31 \mathrm{kcal} / \mathrm{mol}$ (MP2/6-31G(d)) since in the absence of steric interactions the favorable delocalization term would have afforded a more negative value. Similarly, the component of $\Delta E_{90^{\circ}}$ due to loss of delocalization is $>1.80 \mathrm{kcal} /$ mol (MP2/6-31G(d)).

Upon introduction of a methyl group at the ortho position of the phenyl substituent, structural and energetic changes take place which are evident in Table 3. With the smallest basis set used, the geometry of 4-(o-tolyl)pyridine converges at $\theta=90^{\circ}$ with zero imaginary frequencies. However, using a larger basis set, the $90^{\circ}$ structure becomes a rotational transition state and the lowest energy structure is canted. RHF/6-31G(d) methods predict the twist angle to be $\theta=66.5^{\circ}$ (average), and MP2/ $6-31 \mathrm{G}(\mathrm{d})$ methods predict this angle to be $\theta=59.6^{\circ}$ (average). As expected, introduction of steric bulk serves to increase the angle between the two ring systems. An average dihedral angle is reported here since this molecule does not have $C_{2}$ symmetry. In all cases, the rotation of the methyl group is optimized and any transition states associated with this motion are not considered. The small values calculated for $\Delta E_{90^{\circ}}$ suggest a 
TABLE 4: Ab Initio Calculations on Neutral 4-(2,6-Dimethylphenyl)pyridine

\begin{tabular}{|c|c|c|c|c|}
\hline \multirow[b]{2}{*}{ method/basis set } & \multicolumn{2}{|c|}{ optimized structure } & \multicolumn{2}{|c|}{ transition-state structure $\left(\theta^{b}=0^{\circ}\right)$} \\
\hline & $\begin{array}{l}\text { energy (hartrees) } \\
\text { (NIMAG) }^{a}\end{array}$ & $\begin{array}{l}\text { geometrical } \\
\text { properties }\end{array}$ & $\begin{array}{c}\Delta E_{0^{d}} \\
(\mathrm{NIMAG})^{a}\end{array}$ & $\begin{array}{l}\text { geometrical } \\
\text { properties }\end{array}$ \\
\hline RHF/3-21G(d) & $\begin{array}{l}-551.220383 \\
(0)\end{array}$ & $\begin{array}{l}\theta^{b}=90^{\circ} \\
\mathrm{C}-\mathrm{C}^{c}=1.496 \AA\end{array}$ & $\begin{array}{l}24.3 \mathrm{kcal} / \mathrm{mol} \\
(2)\end{array}$ & $\mathrm{C}-\mathrm{C}^{c}=1.531 \AA$ \\
\hline RHF/6-31G(d) & $\begin{array}{l}-554.315704 \\
(0)\end{array}$ & $\begin{array}{l}\theta^{b}=90^{\circ} \\
\mathrm{C}-\mathrm{C}^{c}=1.501 \AA\end{array}$ & $\begin{array}{l}21.8 \mathrm{kcal} / \mathrm{mol} \\
(2)\end{array}$ & $\mathrm{C}-\mathrm{C}^{c}=1.527 \AA$ \\
\hline $\mathrm{MP} 2 / 6-31 \mathrm{G}(\mathrm{d})$ & -556.134617 & $\begin{array}{l}\theta^{b}=90^{\circ} \\
\mathrm{C}-\mathrm{C}^{c}=1.484 \AA\end{array}$ & $20.7 \mathrm{kcal} / \mathrm{mol}$ & $\mathrm{C}-\mathrm{C}^{c}=1.512 \AA$ \\
\hline
\end{tabular}

${ }^{a}$ NIMAG $=$ number of imaginary frequencies. ${ }^{b} \theta$ refers to the twist angle between the aryl and pyridyl rings. ${ }^{c} \mathrm{C}-\mathrm{C}$ refers to the carboncarbon bond distance between the aryl and pyridyl rings. ${ }^{d} \Delta E$ refers to the energetic cost of achieving the transition-state structure from the optimized structure.

soft potential energy surface through the $\theta=90^{\circ}$ transition state; this is supported in the frequency calculation where $v_{\text {imaginary }}=$ $25 \mathrm{i} \mathrm{cm}^{-1}(\mathrm{RHF} / 6-31 \mathrm{G}(\mathrm{d}))$. As expected, there is a larger barrier through the $\theta=0^{\circ}$ transition state for 4-(o-tolyl)pyridine than is seen for 4-phenylpyridine. Again, regarding absolute energetic contributions, we can say that for the $\Delta E_{0^{\circ}}$ barrier there is a greater than $8.98 \mathrm{kcal} / \mathrm{mol}(\mathrm{MP} 2(6-31 \mathrm{G}(\mathrm{d}))$ contribution due to sterics.

Table 4 lists the structural and energetic properties of 4-(2,6dimethylphenyl)pyridine. For this model ligand, steric bulk is greatest within the series; this is reflected in the calculated geometry of the lowest energy structure. For all methods, the twist angle optimizes to $\theta=90^{\circ}$ and the frequency calculations applied to the RHF structures indicate zero imaginary frequencies. Due to computational costs, frequency calculations were not attempted with MP2 methods. In accordance with the increase in steric bulk, the barrier through the $\theta=0^{\circ}$ transition state has also increased relative to the previous two model ligands. We note the more than 2-fold increase in $\Delta E_{0^{\circ}}$ for this dimethyl-substituted ligand relative to the monomethyl case. This is reasonable as $C_{2}$ symmetry is maintained for 4-(2,6dimethylphenyl)pyridine and the molecule cannot bend along the 4,7 bond (within the plane of the $\theta=0^{\circ}$ transition state) to reduce steric repulsions. ${ }^{20}$ Again, since delocalization in the $\theta$ $=0^{\circ}$ state is energetically stabilizing, we can say that the energetic contributions to $\Delta E_{0^{\circ}}$ due to sterics alone are greater than $20.7 \mathrm{kcal} / \mathrm{mol}(\mathrm{MP} 2 / 6-31 \mathrm{G}(\mathrm{d}))$. Frequency calculations of RHF optimized structures with $\theta=0^{\circ}$ indicate two imaginary frequencies for the two basis sets used. In both cases, there is a higher energy imaginary frequency $\left(v_{\text {imaginary }}=148 \mathrm{i}\right.$ and $144 \mathrm{i}$ $\mathrm{cm}^{-1}$ for RHF/3-21G(d) and RHF/6-31G(d), respectively) and a lower energy one $\left(v_{\text {imaginary }}=30 \mathrm{i}\right.$ and $27 \mathrm{i} \mathrm{cm}^{-1}$, RHF/3-21G(d) and RHF/6-31G(d), respectively). The higher energy mode corresponds to the expected breaking of the coplanar state as the aryl group rotates with respect to the pyridine ring while the molecule maintains a $C_{2}$ axis. The lower energy mode corresponds to a puckering of the two methyl groups out of the plane of the molecule, resulting in loss of the $C_{2}$ symmetry while maintaining $C_{s}$ symmetry. ${ }^{21}$

Karpfen et al. have recently addressed the importance of using post-Hartree-Fock methods for correctly describing internal rotational barriers in systems where partial conjugation of a single bond changes through a rotational process. ${ }^{17}$ Of particular interest to us is their consideration of biphenyl. This paper sites the earlier work of Head-Gordon and Pople on substituted ethylenes and benzenes ${ }^{22}$ which suggests that it is necessary to include treatment of electron correlation to correctly describe the partial bond-breaking process associated with internal rotation in conjugated molecules. Karpfen et al. have compared the success of several methods which treat electron correlation including MP2 and several DFT functionals. They observe significant differences in the predicted barrier heights (through the $0^{\circ}$ and $90^{\circ}$ transition states) between MP2 and DFT methods. These workers suggest that DFT incorrectly overestimates the stability of planar species, leading to changes in barrier heights. For our purposes, what is most important is a good description of molecular geometry of the lowest energy stationary point for these three molecules. As will be seen (section V), these geometries can be used to model the Franck-Condon states of ligands involved in MLCT transitions. Since the rotational potential energy surface for these molecules is determined by a convolution of energetic factors such as destabilizing sterics and stabilizing conjugation, overestimation of the stability of the planar species not only serves to change barrier heights but also changes the absolute geometry of the ground-state stationary point. Thus, DFT methods predict values of the dihedral angle $\theta$ for biphenyl that are too small $\left(\theta=39^{\circ}\right.$ B-LYP/6-31G(d) versus $\left.\theta=46^{\circ} \mathrm{MP} 2 / 6-31 \mathrm{G}(\mathrm{d})\right)$. In agreement with this result, we have obtained a B-LYP/6-31G(d) geometry for 4-(o-tolyl)pyridine that shows a smaller dihedral angle $\left(\theta=52.3^{\circ}\right.$ (average)) than in the MP2/6-31G(d) geometry where $\theta=59.6^{\circ}$ (Table 3). With these issues in mind, we feel that the MP2/6$31 \mathrm{G}(\mathrm{d})$ ground-state geometries obtained for these three molecules (Tables 2-4) are accurate and, therefore, appropriate for describing the corresponding anion Franck-Condon states (vide infra).

III. Single-Crystal X-ray Structures: Experimental Values for the Ground-State Ligand Twist Angles $(\boldsymbol{\theta})$. To get a sense of the agreement between X-ray structures and calculations, we determined the single-crystal X-ray structures of the three ligands we are modeling, namely, dpb, dotb, and dmesb. Crystallographic details for all three structures are given in Table 1 , with pertinent bond distances and dihedral angles $(\theta)$ listed in Table 5. ORTEP drawings of the compounds are shown in Figures 1, 2, and 3 for dpb, dotb, and dmesb, respectively. All three molecules crystallize in monoclinic space groups. Each compound lies on an inversion center that bisects the $\mathrm{C}-\mathrm{C}$ bond at the 2 and $2^{\prime}$ positions of the pyridyl rings, thus making the two halves of the molecule identical by symmetry. Although the inversion symmetry is crystallographically imposed, it does serve to further validate our approximation of considering only one pyridyl fragment of the molecule for the computational analysis.

Bond distances within both the pyridyl and aryl fragments are largely unremarkable: $\mathrm{C}-\mathrm{C}$ double-bond distances are virtually identical at ca. 1.39(1) $\AA$ for all three compounds, as are the $\mathrm{C}-\mathrm{N}$ bonds (average $=1.340(5) \AA$ ). In addition, the $\mathrm{C}-\mathrm{C}$ single bonds (e.g., $\mathrm{C}(1)-\mathrm{C}\left(1^{*}\right)$ and aryl-methyl linkages) are also very similar for the three structures. The $\mathrm{C}(3)-\mathrm{C}(6)$ bond linking the pyridyl and aryl fragments shows a slight contraction from $1.495(2) \AA(\mathrm{dpb})$ to $1.488(2)$ (dotb) and $1.485(4) \AA$ (dmesb). This trend, although not pronounced, is 
TABLE 5: Selected Bond Distances and Angles for dpb, dotb, and dmesb

\begin{tabular}{lccc}
\hline & \multicolumn{3}{c}{ distance $(\AA)$} \\
\cline { 2 - 4 } & $\mathrm{dpb}$ & dotb & dmesb \\
\hline $\mathrm{N}(1)-\mathrm{C}(1)$ & $1.345(2)$ & $1.349(2)$ & $1.346(3)$ \\
$\mathrm{N}(1)-\mathrm{C}(5)$ & $1.335(2)$ & $1.335(2)$ & $1.332(3)$ \\
$\mathrm{C}(1)-\mathrm{C}\left({ }^{*} 1\right)$ & $1.489(3)$ & $1.491(2)$ & $1.490(5)$ \\
$\mathrm{C}(1)-\mathrm{C}(2)$ & $1.392(2)$ & $1.396(2)$ & $1.389(3)$ \\
$\mathrm{C}(2)-\mathrm{C}(3)$ & $1.394(2)$ & $1.397(2)$ & $1.388(4)$ \\
$\mathrm{C}(3)-\mathrm{C}(4)$ & $1.395(2)$ & $1.394(2)$ & $1.395(4)$ \\
$\mathrm{C}(4)-\mathrm{C}(5)$ & $1.381(2)$ & $1.386(2)$ & $1.386(4)$ \\
$\mathrm{C}(3)-\mathrm{C}(6)$ & $1.495(2)$ & $1.488(2)$ & $1.485(4)$ \\
$\mathrm{C}(6)-\mathrm{C}(7)$ & $1.391(2)$ & $1.400(2)$ & $1.396(4)$ \\
$\mathrm{C}(7)-\mathrm{C}(8)$ & $1.392(2)$ & $1.383(2)$ & $1.394(4)$ \\
$\mathrm{C}(8)-\mathrm{C}(9)$ & $1.378(2)$ & $1.387(2)$ & $1.396(4)$ \\
$\mathrm{C}(9)-\mathrm{C}(10)$ & $1.377(2)$ & $1.386(2)$ & $1.381(4)$ \\
$\mathrm{C}(10)-\mathrm{C}(11)$ & $1.385(2)$ & $1.401(2)$ & $1.387(4)$ \\
$\mathrm{C}(6)-\mathrm{C}(11)$ & $1.394(2)$ & $1.411(2)$ & $1.418(4)$ \\
$\mathrm{C}(11)-\mathrm{C}(12)$ & & $1.505(2)$ & \\
$\mathrm{C}(9)-\mathrm{C}(13)$ & & & $1.507(4)$ \\
$\mathrm{C}(11)-\mathrm{C}(14)$ & & & $1.500(4)$ \\
$\mathrm{C}(7)-\mathrm{C}(12)$ & & & $1.515(4)$ \\
dihedral angle & $9.60^{\circ}$ & $51.05^{\circ}$ & $89.14^{\circ}$
\end{tabular}

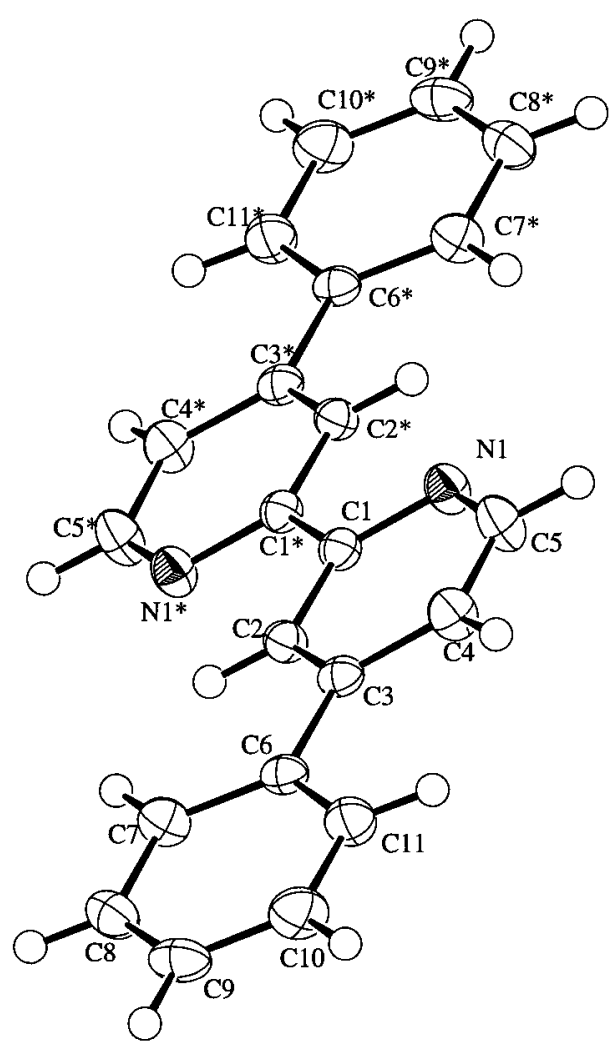

Figure 1. ORTEP representation of 4,4'-diphenyl-2,2'-bipyridine (dpb) from a single-crystal X-ray structure determination. See Table 1 and Table 5 for crystallographic and structural details, respectively.

likely a consequence of reduced steric interactions due to the increase in dihedral angle on going from dpb to dmesb (vide infra). There are no other obvious trends noted except for nearly uniformly larger bond distances for the dotb structure. However, this corresponds to only $0.01 \AA$ at its maximum and is not considered to be very significant. Internal bond angles (available in Supporting Information) exhibit no significant trends and are consistent with expectations. In general, the bond distances and angles obtained from the X-ray structure determinations compare favorably with those determined from the highest level calculations described above. Focusing solely on the $\mathrm{C}(3)-\mathrm{C}(6)$ pyridyl-phenyl bond, we find for 4-phenylpyr-

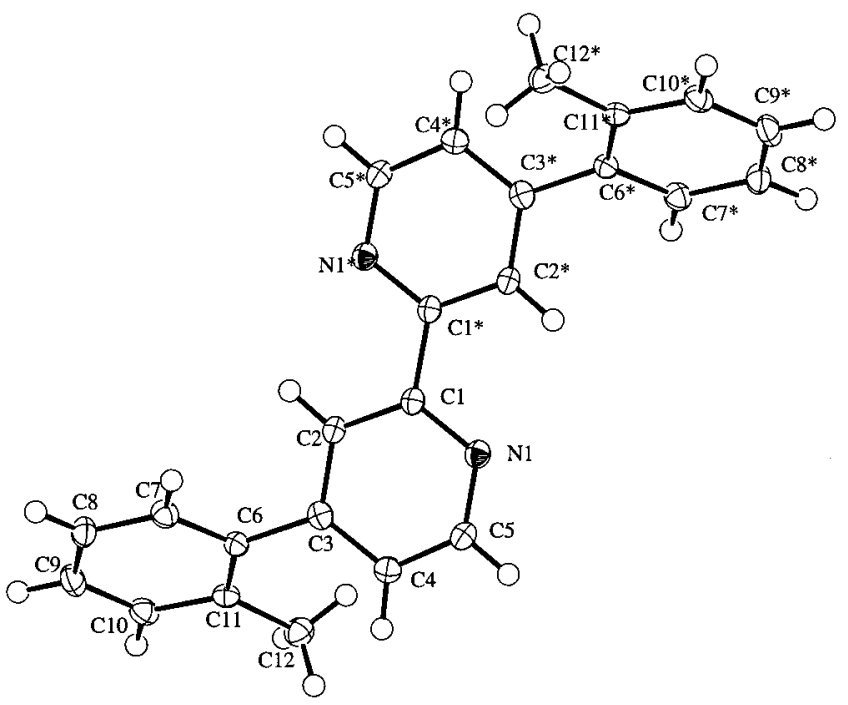

Figure 2. ORTEP representation of 4,4'-di-o-tolyl-2,2'-bipyridine (dotb) from a single-crystal X-ray structure determination. See Table 1 and Table 5 for crystallographic and structural details, respectively.

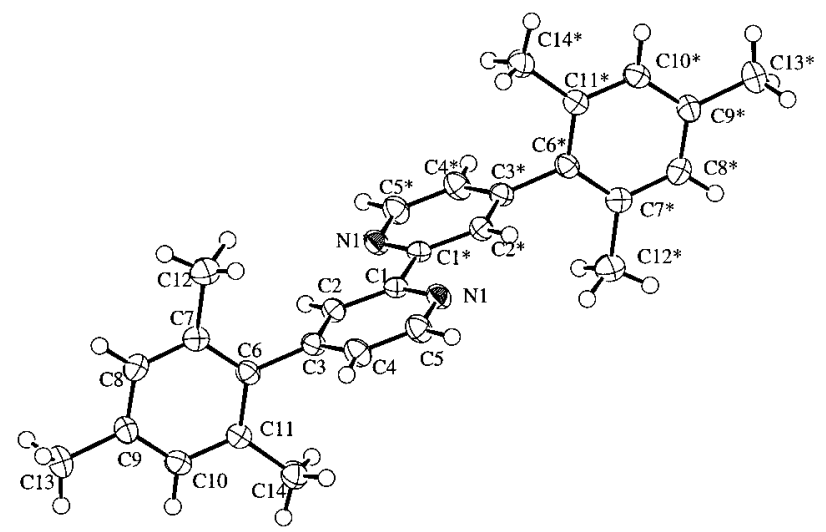

Figure 3. ORTEP representation of 4,4'-dimesityl-2,2'-bipyridine (dmesb) from a single-crystal X-ray structure determination. See Table 1 and Table 5 for crystallographic and structural details, respectively.

idine calculated values of $1.477 \AA$ (MP2/6-31G(d)), compared to the experimental value of $1.495(5) \AA$. We expect that the larger experimental bond length is related to the nearly coplanar geometry adopted by the ligand in the crystalline form. As will be discussed, packing forces in the crystal favor planarity at the expense of steric interactions between protons ortho to this bond. As a result, the phenyl and pyridyl rings separate slightly to reduce unfavorable steric interactions. The agreement is better for the monomethyl- and dimethyl-substituted phenyl compounds. For the former, calculated values of $1.481 \AA$ (MP2/ 6-31G(d)) agree well with the experimentally determined distance of $1.488(2) \AA$. The MP2/6-31G(d) value of $1.484 \AA$ for 4-(2,6-dimethylphenyl)pyridine is nearly identical to the observed value of 1.485(4) $\AA$ for 4,4'-dimesityl-2,2'-bipyridine.

For our purposes, the most interesting aspect of the structures of these compounds is the dihedral angle between the pyridyl and aryl rings; these are also listed in Table 5. It is observed that the systematic inclusion of methyl groups on the aryl substituent serves to increase this angle, consistent with what was anticipated from our calculations. The most striking agreement occurs for dmesb, with the experimental value of $89.1^{\circ}$ lying within $1^{\circ}$ of the value of $90^{\circ}$ predicted by all of the methods and basis sets described above. Closest contacts between the aryl and pyridyl fragments occur at the positions ortho to the $\mathrm{C}(3)-\mathrm{C}(6)$ bond, with an observed $\mathrm{H}---\mathrm{H}$ distance 
of $2.90 \AA$. An examination of the packing diagram for dmesb did not reveal any significant intermolecular interactions. This is no doubt a factor contributing to the remarkable agreement between the X-ray structure and a calculation of what amounts to the compound's structure in the gas phase.

In the case of dotb, the agreement between the calculated and crystallographically determined dihedral angle is still quite good, although a slight difference is observed. The experimental angle of $51.05^{\circ}$ is approximately $8^{\circ}$ smaller than the $59.6^{\circ}$ angle obtained from the MP2/6-31G(d) calculation. Intramolecular contacts are somewhat more significant in the case of the dotb structure: ortho $\mathrm{H}-\mathrm{-}-\mathrm{H}$ and $\mathrm{C}-\mathrm{-}_{-\mathrm{H}} \mathrm{H}$ distances of 2.58 and 2.84 $\AA$ were found, respectively, compared to 2.49 and $3.01 \AA$ for the corresponding distances from the calculation. Although no significant intermolecular interactions were noted in the packing diagram, it is reasonable to assume that packing forces are at least partly responsible for the discrepancy between the experimental and calculated values.

The poorest agreement between theory and experiment occurs in the case of the unmethylated dpb. While the gas-phase calculation predicts a dihedral angle of ca. $45^{\circ}$, representing a balance between steric and electronic factors, the X-ray structure reveals an almost coplanar structure with $\theta=9.6^{\circ}$. A very short ortho H- - -H distance of $2.07 \AA$ is observed, compared to a distance of $2.48 \AA$ derived from the $\mathrm{MP} 2 / 6-31 \mathrm{G}(\mathrm{d})$ calculation. Since the calculation is carried out in the absence of intermolecular interactions, we believe that the marked deviation seen in the case of $\mathrm{dpb}$ arises due to packing forces in the lattice. An examination of the packing diagram for dpb reveals a herringbone-type motif common for biphenyl complexes, an arrangement that provides for facile intermolecular interactions. This agrees with the literature concerning the crystallographic packing of biphenyl and related compounds. ${ }^{23}$ The favorable energetic effect of these intermolecular interactions are apparently sufficient to overcome the unfavorable intramolecular steric factors, thereby leading to a smaller dihedral angle than that predicted by the calculations. However, these results for $\mathrm{dpb}$ notwithstanding, we find that the singlecrystal X-ray structures of dpb, dotb, and dmesb are in reasonable agreement with the calculations.

IV. Ground-State Anion Calculations: Establishing the Degree of Planarity/Delocalization for Reduced Model Ligands. As was previously discussed, spectroscopic evidence suggests that the ligand electronic structure of the ${ }^{3} \mathrm{MLCT}$ excited state of $\left[\mathrm{Ru}(\mathrm{dpb})_{3}\right]\left(\mathrm{PF}_{6}\right)_{2}$ is best described as delocalized between the bipyridine and its substituent phenyl rings. ${ }^{7}$ In addition, this delocalization is attenuated as steric bulk is introduced into ortho positions on the aryl substituents of the ligands. We have used ab initio and DFT calculations to explore how the geometry and electronic structure of singly reduced ligands change with the stepwise increase in steric hindrance to planarity.

Before proceeding, it is worth discussing the choice of theoretical methods used. Since we are interested in the singly reduced forms of these model ligands, we are dealing with openshell systems that have a doublet spin state. Our first choice was unrestricted Hartree-Fock (UHF) methods, which in general yield useful molecular orbital information. However, as is evident from the values of $\left\langle S^{2}\right\rangle$ given in Tables 6-9, there is severe spin contamination of the doublet state with higher lying quartet states for each UHF calculation that was carried out. The quantity $\left\langle S^{2}\right\rangle$ is the eigenvalue for the total spin operator:

$$
\left\langle S^{2}\right\rangle=S(S+1)
$$

For a pure doublet, $\left\langle S^{2}\right\rangle=0.7500$, whereas for the UHF calculations $\left\langle S^{2}\right\rangle$ is as large as 1.3. We include these calculations here for two reasons. First, their predictions of the geometrical properties of these model ligands are consistent with other, less spin-contaminated methods. Second, the UHF methods appear to reasonably describe relative energies of Franck-Condonstate relaxation for the model ligands discussed in section $\mathrm{V}$. Because of the spin contamination, however, other methods were needed to check the qualitative conclusions from the UHF calculations. Unrestricted DFT calculations using two different functionals ( $\mathrm{SVWN}^{11}$ and B-LYP ${ }^{12}$ ) were used and in each case show very little spin contamination. Information from these calculations is discussed in comparison to the spin-contaminated Hartree-Fock results. Finally, restricted open-shell HartreeFock (ROHF) and in some cases restricted open-shell MP2 (ROMP2) calculations were done. These allow a comparison of results obtained with DFT and Hartree-Fock methods without the complications associated with spin contamination.

Table 6 shows the energies and inter-ring dihedral angles of the singly reduced forms of the three ligands with each of the methods and basis sets used. Also included is the optimized inter-ring $\mathrm{C}-\mathrm{C}$ bond distance in order to illustrate geometric differences arising from the individual theoretical methods. These calculations are all geometry optimizations with no constraints on the central dihedral angle. For each method/ basis-set combination used, the geometry of [4-phenylpyridine $]^{-}$ has the two rings coplanar $\left(\theta=0^{\circ}\right)$, in contrast to the $\theta \sim 44^{\circ}$ seen for the neutral species. To illustrate the origin of this planarity, we can invoke a resonance picture often used in the context of reduced biphenyl in which there is double-bond character between the two ring systems: ${ }^{18}$

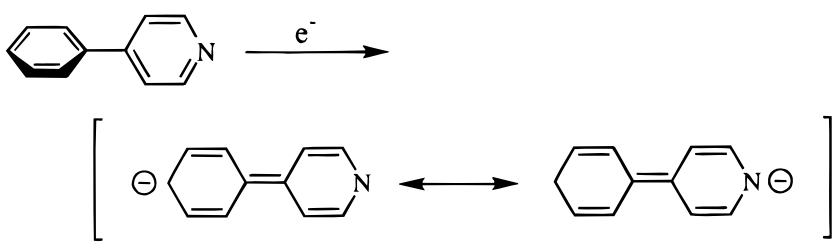

Comparing inter-ring bond distances calculated with HartreeFock methods shows a significant shortening of the central $\mathrm{C}-\mathrm{C}$ bond upon reduction, which is consistent with the above picture. For example, the RHF/6-31G(d) optimized geometry predicts $1.490 \AA$ for 4-phenylpyridine, whereas the UHF/6-31+G(d) optimized geometry of the corresponding monoanion predicts $1.419 \AA$. Figure 4 (left) shows an orbital picture generated for the singly occupied highest molecular orbital (SOMO) of [4-phenylpyridine] ${ }^{-}$calculated at the UHF/6-31G(d) level. ${ }^{24} \mathrm{We}$ note the similarity to the resonance picture shown above with central and alternating $\pi$-bond character and significant orbital coefficients at the terminal nitrogen and carbon atoms.

With the introduction of a methyl group as in [4-(o-tolyl)pyridine $]^{-}$the ability to achieve a fully coplanar structure is energetically unfavorable. Table 6 indicates that the lowest energy geometry for the anion is one in which $\theta \sim 25^{\circ}$. There is some variation in the predicted angle depending on the basis set used. For example, calculations using the $3-21+\mathrm{G}(\mathrm{d})$ basis set show a slightly larger angle $\left(\theta \sim 32^{\circ}\right)$. In addition, within a given basis set there is also some variation in angle depending on the method that was used. The B-LYP functional consistently predicts the largest angle, while UHF methods predict the smallest. Nevertheless, the calculated angles agree within $4^{\circ}$ for each basis set used. While delocalization is expected to 
TABLE 6: Energy and Structural Properties of Singly Reduced 4-Phenylpyridine, 4-(o-Tolyl)pyridine, and 4-(2,6-Dimethylphenyl)pyridine

\begin{tabular}{|c|c|c|c|c|c|c|}
\hline \multirow[b]{2}{*}{ method/basis set } & \multicolumn{2}{|c|}{${\text { (4-phenylpyridine) })^{-}}^{-}$} & \multicolumn{2}{|c|}{$\left(4-(o \text {-tolyl)pyridine })^{-}\right.$} & \multicolumn{2}{|c|}{${\text { (4-(2,6-dimethylphenyl)pyridine) })^{-}}^{-}$} \\
\hline & $\begin{array}{l}\text { energy (hartrees) } \\
\text { spin contamination }\end{array}$ & $\begin{array}{l}\text { geometrical } \\
\text { properties }\end{array}$ & $\begin{array}{l}\text { energy (hartrees) } \\
\text { spin contamination }\end{array}$ & $\begin{array}{l}\text { geometrical } \\
\text { properties }\end{array}$ & $\begin{array}{l}\text { energy (hartrees) } \\
\text { spin contamination }\end{array}$ & $\begin{array}{l}\text { geometrical } \\
\text { properties }\end{array}$ \\
\hline $\mathrm{UHF} / 3-21 \mathrm{G}(\mathrm{d})$ & $\begin{array}{l}-473.541554^{a} \\
\left\langle S^{2}\right\rangle=1.261\end{array}$ & $\begin{array}{l}\theta=0^{\circ} \\
\mathrm{C}-\mathrm{C}=1.415 \AA\end{array}$ & $\begin{array}{l}-512.351475^{a} \\
\left\langle S^{2}\right\rangle=1.285\end{array}$ & $\begin{array}{l}\theta=24.8^{\circ}(\mathrm{av}) \\
\mathrm{C}-\mathrm{C}=1.423 \AA\end{array}$ & $\begin{array}{l}-551.162868^{a} \\
\left\langle S^{2}\right\rangle=1.312\end{array}$ & $\begin{array}{l}\theta=40.3^{\circ} \\
\mathrm{C}-\mathrm{C}=1.434 \AA\end{array}$ \\
\hline $\mathrm{ROHF} / 3-21 \mathrm{G}(\mathrm{d})$ & $\begin{array}{l}-473.523052 \\
\left\langle S^{2}\right\rangle=0.7500\end{array}$ & $\begin{array}{l}\theta=0^{\circ} \\
\mathrm{C}-\mathrm{C}=1.424 \AA\end{array}$ & $\begin{array}{l}-512.332650 \\
\left\langle S^{2}\right\rangle=0.7500\end{array}$ & $\begin{array}{l}\theta=27.4^{\circ}(\mathrm{av}) \\
\mathrm{C}-\mathrm{C}=1.433 \AA\end{array}$ & $\begin{array}{l}-551.144476 \\
\left\langle S^{2}\right\rangle=0.7500\end{array}$ & $\begin{array}{l}\theta=45.4^{\circ} \\
\mathrm{C}-\mathrm{C}=1.449 \AA\end{array}$ \\
\hline USVWN/3-21G(d) & $\begin{array}{l}-474.004458 \\
\left\langle S^{2}\right\rangle=0.7514\end{array}$ & $\begin{array}{l}\theta=0^{\circ} \\
\mathrm{C}-\mathrm{C}=1.428 \AA\end{array}$ & $\begin{array}{l}-512.888536 \\
\left\langle S^{2}\right\rangle=0.7514\end{array}$ & $\begin{array}{l}\theta=25.6^{\circ}(\mathrm{av}) \\
\mathrm{C}-\mathrm{C}=1.433 \AA\end{array}$ & $\begin{array}{l}-551.773414 \\
\left\langle S^{2}\right\rangle=0.7513\end{array}$ & $\begin{array}{l}\theta=39.5^{\circ} \\
\mathrm{C}-\mathrm{C}=1.439 \AA\end{array}$ \\
\hline UB-LYP/3-21G(d) & $\begin{array}{l}-476.476184 \\
\left\langle S^{2}\right\rangle=0.7536\end{array}$ & $\begin{array}{l}\theta=0^{\circ} \\
\mathrm{C}-\mathrm{C}=1.450 \AA\end{array}$ & $\begin{array}{l}-515.544145 \\
\left\langle S^{2}\right\rangle=0.7534\end{array}$ & $\begin{array}{l}\theta=28.2^{\circ}(\mathrm{av}) \\
\mathrm{C}-\mathrm{C}=1.457 \AA\end{array}$ & $\begin{array}{l}-554.612988 \\
\left\langle S^{2}\right\rangle=0.7530\end{array}$ & $\begin{array}{l}\theta=44.1^{\circ} \\
\mathrm{C}-\mathrm{C}=1.466 \AA\end{array}$ \\
\hline $\mathrm{UHF} / 3-21+\mathrm{G}(\mathrm{d})$ & $\begin{array}{l}-473.610077^{a} \\
\left\langle S^{2}\right\rangle=1.17\end{array}$ & $\begin{array}{l}\theta=0^{\circ} \\
\mathrm{C}-\mathrm{C}=1.419 \AA\end{array}$ & $\begin{array}{l}-512.421493^{a} \\
\left\langle S^{2}\right\rangle=1.212\end{array}$ & $\begin{array}{l}\theta=30.7^{\circ}(\mathrm{av}) \\
\mathrm{C}-\mathrm{C}=1.432 \AA\end{array}$ & $\begin{array}{l}-551.236586^{a} \\
\left\langle S^{2}\right\rangle=1.259\end{array}$ & $\begin{array}{l}\theta=50.1^{\circ} \\
\mathrm{C}-\mathrm{C}=1.456 \AA\end{array}$ \\
\hline $\mathrm{ROHF} / 3-21+\mathrm{G}(\mathrm{d})$ & $\begin{array}{l}-473.595677 \\
\left\langle S^{2}\right\rangle=0.7500\end{array}$ & $\begin{array}{l}\theta=0^{\circ} \\
\mathrm{C}-\mathrm{C}=1.428 \AA\end{array}$ & $\begin{array}{l}-512.406365 \\
\left\langle S^{2}\right\rangle=0.7500\end{array}$ & $\begin{array}{l}\theta=33.5^{\circ}(\mathrm{av}) \\
\mathrm{C}-\mathrm{C}=1.440 \AA\end{array}$ & $\begin{array}{l}-551.221936 \\
\left\langle\mathrm{~S}^{2}\right\rangle=0.7500\end{array}$ & $\begin{array}{l}\theta=55.5^{\circ} \\
\mathrm{C}-\mathrm{C}=1.465 \AA\end{array}$ \\
\hline USVWN/3-21+G(d) & $\begin{array}{l}-474.077738 \\
\left\langle S^{2}\right\rangle=0.7512\end{array}$ & $\begin{array}{l}\theta=0^{\circ} \\
\mathrm{C}-\mathrm{C}=1.429 \AA\end{array}$ & $\begin{array}{l}-512.964072 \\
\left\langle S^{2}\right\rangle=0.7512\end{array}$ & $\begin{array}{l}\theta=30.7^{\circ}(\mathrm{av}) \\
\mathrm{C}-\mathrm{C}=1.435 \AA\end{array}$ & $\mathrm{NC}^{b}$ & $\mathrm{NC}^{b}$ \\
\hline UB-LYP/3-21+G(d) & $\begin{array}{l}-476.559654 \\
\left\langle S^{2}\right\rangle=0.7530\end{array}$ & $\begin{array}{l}\theta=0^{\circ} \\
\mathrm{C}-\mathrm{C}=1.452 \AA\end{array}$ & $\begin{array}{l}-515.630130 \\
\left\langle S^{2}\right\rangle=0.7528\end{array}$ & $\begin{array}{l}\theta=34.0^{\circ}(\mathrm{av}) \\
\mathrm{C}-\mathrm{C}=1.460 \AA\end{array}$ & $\begin{array}{l}-554.703051 \\
\left\langle S^{2}\right\rangle=0.7525\end{array}$ & $\begin{array}{l}\theta=50.1^{\circ} \\
\mathrm{C}-\mathrm{C}=1.471 \AA\end{array}$ \\
\hline $\mathrm{UHF} / 6-31 \mathrm{G}(\mathrm{d})$ & $\begin{array}{l}-476.209469^{a} \\
\left\langle S^{2}\right\rangle=1.216\end{array}$ & $\begin{array}{l}\theta=0^{\circ} \\
\mathrm{C}-\mathrm{C}=1.416 \AA\end{array}$ & $\begin{array}{l}-515.235673^{a} \\
\left\langle S^{2}\right\rangle=1.243\end{array}$ & $\begin{array}{l}\theta=22.7^{\circ}(\mathrm{av}) \\
\mathrm{C}-\mathrm{C}=1.425 \AA\end{array}$ & $\begin{array}{l}-554.262006^{a} \\
\left\langle S^{2}\right\rangle=1.28\end{array}$ & $\begin{array}{l}\theta=39.2^{\circ} \\
\mathrm{C}-\mathrm{C}=1.436 \AA\end{array}$ \\
\hline UMP2/6-31G(d) & $\begin{array}{l}-477.754176 \\
\left\langle S^{2}\right\rangle=1.030\end{array}$ & $\begin{array}{l}\theta=0^{\circ} \\
\mathrm{C}-\mathrm{C}=1.431 \AA\end{array}$ & $\begin{array}{l}-516.893113 \\
\left\langle S^{2}\right\rangle=1.043\end{array}$ & $\begin{array}{l}\theta=28.6^{\circ}(\mathrm{av}) \\
\mathrm{C}-\mathrm{C}=1.434 \AA\end{array}$ & $\begin{array}{l}-556.056498 \\
\left\langle S^{2}\right\rangle=1.056\end{array}$ & $\begin{array}{l}\theta=42.6^{\circ} \\
\mathrm{C}-\mathrm{C}=1.438 \AA\end{array}$ \\
\hline ROHF/6-31G(d) & $\begin{array}{l}-476.191794 \\
\left\langle S^{2}\right\rangle=0.7500\end{array}$ & $\begin{array}{l}\theta=0^{\circ} \\
\mathrm{C}-\mathrm{C}=1.426 \AA\end{array}$ & $\begin{array}{l}-515.217571 \\
\left\langle S^{2}\right\rangle=0.7500\end{array}$ & $\begin{array}{l}\theta=25.3^{\circ}(\mathrm{av}) \\
\mathrm{C}-\mathrm{C}=1.434 \AA\end{array}$ & $\begin{array}{l}-554.244243 \\
\left\langle S^{2}\right\rangle=0.7500\end{array}$ & $\begin{array}{l}\theta=44.0^{\circ} \\
\mathrm{C}-\mathrm{C}=1.449 \AA\end{array}$ \\
\hline USVWN/6-31G(d) & $\begin{array}{l}-476.625185 \\
\left\langle S^{2}\right\rangle=0.751\end{array}$ & $\begin{array}{l}\theta=0^{\circ} \\
\mathrm{C}-\mathrm{C}=1.426 \AA\end{array}$ & $\begin{array}{l}-515.720533 \\
\left\langle S^{2}\right\rangle=0.7513\end{array}$ & $\begin{array}{l}\theta=23.1^{\circ}(\mathrm{av}) \\
\mathrm{C}-\mathrm{C}=1.432 \AA\end{array}$ & $\begin{array}{l}-554.815371 \\
\left\langle S^{2}\right\rangle=0.7512\end{array}$ & $\begin{array}{l}\theta=38.6^{\circ} \\
\mathrm{C}-\mathrm{C}=1.438 \AA\end{array}$ \\
\hline UB-LYP/6-31G(d) & $\begin{array}{l}-479.122727 \\
\left\langle S^{2}\right\rangle=0.7536\end{array}$ & $\begin{array}{l}\theta=0^{\circ} \\
\mathrm{C}-\mathrm{C}=1.448 \AA\end{array}$ & $\begin{array}{l}-518.404664 \\
\left\langle S^{2}\right\rangle=0.7534\end{array}$ & $\begin{array}{l}\theta=26.7^{\circ}(\mathrm{av}) \\
\mathrm{C}-\mathrm{C}=1.455 \AA\end{array}$ & $\begin{array}{l}-557.686668 \\
\left\langle S^{2}\right\rangle=0.7529\end{array}$ & $\begin{array}{l}\theta=44.2^{\circ} \\
\mathrm{C}-\mathrm{C}=1.465 \AA\end{array}$ \\
\hline $\mathrm{UHF} / 6-31+\mathrm{G}(\mathrm{d})$ & $\begin{array}{l}-476.236776^{a} \\
\left\langle S^{2}\right\rangle=1.16\end{array}$ & $\begin{array}{l}\theta=0^{\circ} \\
\mathrm{C}-\mathrm{C}=1.419 \AA\end{array}$ & $\begin{array}{l}-515.261904 \\
\left\langle S^{2}\right\rangle=1.199\end{array}$ & $\begin{array}{l}\theta=23.8^{\circ}(\mathrm{av}) \\
\mathrm{C}-\mathrm{C}=1.430 \AA\end{array}$ & $\begin{array}{l}-554.287804 \\
\left\langle S^{2}\right\rangle=1.252\end{array}$ & $\begin{array}{l}\theta=42.5^{\circ} \\
\mathrm{C}-\mathrm{C}=1.447 \AA\end{array}$ \\
\hline $\mathrm{ROHF} / 6-31+\mathrm{G}(\mathrm{d})$ & $\begin{array}{l}-476.222331 \\
\left\langle S^{2}\right\rangle=0.7500\end{array}$ & $\begin{array}{l}\theta=0^{\circ} \\
\mathrm{C}-\mathrm{C}=1.428 \AA\end{array}$ & $\begin{array}{l}-515.246411 \\
\left\langle S^{2}\right\rangle=0.7500\end{array}$ & $\begin{array}{l}\theta=26.5^{\circ}(\mathrm{av}) \\
\mathrm{C}-\mathrm{C}=1.438 \AA\end{array}$ & $\begin{array}{l}-554.272409 \\
\left\langle S^{2}\right\rangle=0.7500\end{array}$ & $\begin{array}{l}\theta=47.6^{\circ} \\
\mathrm{C}-\mathrm{C}=1.458 \AA\end{array}$ \\
\hline USVWN/6-31+G(d) & $\begin{array}{l}-476.659684 \\
\left\langle S^{2}\right\rangle=0.7512\end{array}$ & $\begin{array}{l}\theta=0^{\circ} \\
\mathrm{C}-\mathrm{C}=1.428 \AA\end{array}$ & $\begin{array}{l}-515.754371 \\
\left\langle S^{2}\right\rangle=0.7512\end{array}$ & $\begin{array}{l}\theta=24.6^{\circ}(\mathrm{av}) \\
\mathrm{C}-\mathrm{C}=1.434 \AA\end{array}$ & $\mathrm{NC}^{b}$ & $\mathrm{NC}^{b}$ \\
\hline UB-LYP/6-31+G(d) & $\begin{array}{l}-479.165241 \\
\left\langle S^{2}\right\rangle=0.7531\end{array}$ & $\begin{array}{l}\theta=0^{\circ} \\
\mathrm{C}-\mathrm{C}=1.450 \AA\end{array}$ & $\begin{array}{l}-518.446433 \\
\left\langle S^{2}\right\rangle=0.7534\end{array}$ & $\begin{array}{l}\theta=28.1^{\circ}(\mathrm{av}) \\
\mathrm{C}-\mathrm{C}=1.458 \AA\end{array}$ & $\begin{array}{l}-557.728727 \\
\left\langle S^{2}\right\rangle=0.7527\end{array}$ & $\begin{array}{l}\theta=46.0^{\circ} \\
\mathrm{C}-\mathrm{C}=1.468 \AA\end{array}$ \\
\hline
\end{tabular}

${ }^{a}$ For these stationary points, the analytic Hessian was calculated and diagonalized and the number of imaginary frequencies equals zero. ${ }^{b}$ Convergence was not achieved in these calculations.
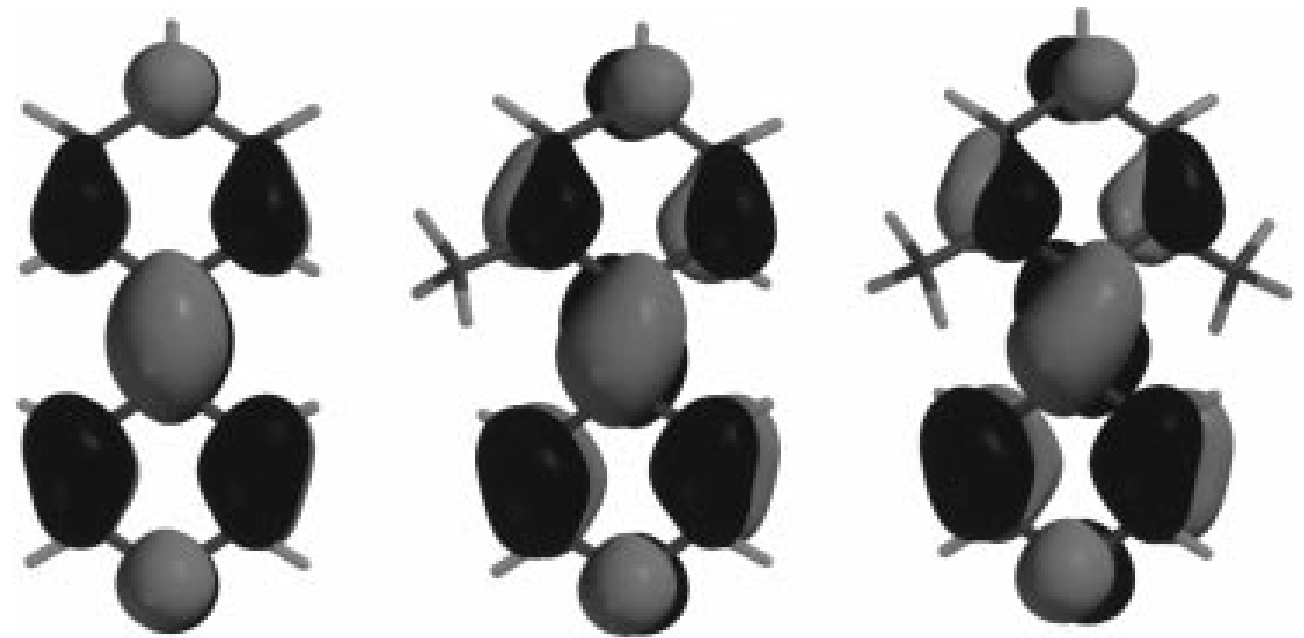

Figure 4. Singly occupied molecular orbitals (SOMOs) for [4-phenylpyridine $]^{-}$(left), [4-(o-tolyl)pyridine) $]^{-}$(center), and [4-(2,6-dimethylphenyl)pyridine $^{-}$(right) based on UHF/6-31G(d) calculations. The different shadings indicate the relative phases of the molecular orbital.

be attenuated due to the nonzero dihedral angle, there is clearly a driving force in the anion for achieving a more planar overall structure relative to the $\theta \sim 66^{\circ}$ geometry in the neutral. As was seen for 4-phenylpyridine and its corresponding anion, 4- $(o-$ tolyl)pyridine shows a significant shortening of the central $\mathrm{C}-\mathrm{C}$ bond upon reduction (1.496 $\AA$ for the neutral (RHF/6-31G(d)) versus $1.430 \AA$ (UHF/6-31+G(d)) for the reduced species), suggesting conjugation similar to that discussed above. A molecular orbital picture generated for the [4-(o-tolyl)pyridine $]^{-}$ SOMO (Figure 4, center) is qualitatively similar to that seen above for [4-phenylpyridine] ${ }^{-}$with an indication of $\pi$ character in the central $\mathrm{C}-\mathrm{C}$ bond. 


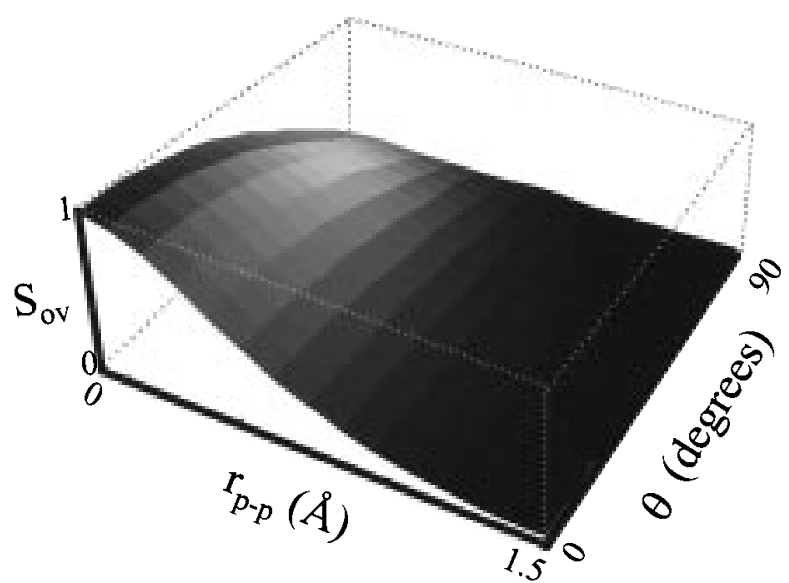

Figure 5. Graphical representation of the change in overlap integral $S$ of two carbon p orbitals as a function of both distance $(r)$ and dihedral angle $(\theta)$. See text for further details.

As expected, increasing the steric bulk from one to two methyl groups, as in going from [4-(o-tolyl)pyridine $]^{-}$to [4-(2,6dimethylphenyl)pyridine $]^{-}$, causes the central dihedral angle of the anion ground state to increase further (Table 6). This, coupled with a lengthening of the central $\mathrm{C}-\mathrm{C}$ bond distance as compared to [4-(o-tolyl)pyridine $]^{-}$and [4-phenylpyridine $]^{-}$, necessarily represents a significant reduction in the $\pi$ overlap of the two ring systems. Nevertheless, there is nonzero overlap and, as in the two previous molecules, some driving force for achieving a more conjugated/delocalized geometry for the reduced species despite the unfavorable steric interactions. While calculations on the neutral predict the inter-ring dihedral angle to be $\theta=90^{\circ}$, this angle is significantly smaller $\left(\theta \sim 45^{\circ}\right)$ for the reduced species. Similar to [4-(o-tolyl)pyridine $]^{-}$, the calculated angle is somewhat dependent on method/basis set used. However, within each basis set there is a less than $6^{\circ}$ spread in calculated values of $\theta$. Again, the $3-21+\mathrm{G}(\mathrm{d})$ basis set predicts higher values, and within a given basis set UBLYP and ROHF methods predict slightly larger angles than UHF and USVWN methods. As in the previously discussed molecules, there is a calculated shortening of the central $\mathrm{C}-\mathrm{C}$ bond upon reduction. This, in conjunction with the predicted dihedral angle of $\theta \sim 45^{\circ}$, is consistent with the idea that there is at least partial conjugation/delocalization in [4-(2,6-dimethylphenyl)pyridine $]^{-}$. The molecular orbital picture generated for the SOMO of this molecule seen in Figure 4 (right) is qualitatively similar to those seen for [4-(o-tolyl)pyridine] ${ }^{-}$and [4-phenylpyridine $]^{-}$. It shows some $\pi$ character in the central $\mathrm{C}-\mathrm{C}$ bond despite the larger dihedral angle.

The degree to which conjugation/delocalization is lost upon systematic introduction of steric bulk about the central $\mathrm{C}-\mathrm{C}$ bond can be gauged by calculating the overlap integral $S$ of two carbon p orbitals as a function of distance $r$ as well as dihedral angle $\theta$ between orbitals. The $\theta$ dependence of $S$ is governed by a simple cosine relationship:

$$
S(\theta)=\cos \theta
$$

The overlap integral of two carbon $2 \mathrm{p}$ orbitals as a function of $r$ is somewhat more complicated and is given in the following equation: ${ }^{25}$

$$
S(r)=\left(1+s+\frac{s^{2}}{5}+\frac{s^{3}}{15}\right) \mathrm{e}^{-s} \text { where } \mathrm{s}=\frac{Z^{*} r}{n a_{\mathrm{o}}}
$$

Here, $Z^{*}$ is the effective atomic number approximated as 5.70 for carbon, $n$ is the principle quantum number of carbon, and $a_{\mathrm{o}}$ is the Bohr radius. Combining these two equations yields

$$
S(r, \theta)=\cos \theta\left(1+s+\frac{s^{2}}{5}+\frac{s^{3}}{15}\right) \mathrm{e}^{-s}
$$

A plot of this overlap for a selected region of $r$ and $\theta$ is shown in Figure 5. We can use this equation to determine how much $S$ is attenuated across this series as steric bulk is added. Using UMP2/6-31G(d) values for $r$ and $\theta$ (Table 5), we calculate a $13 \%$ attenuation of $S$ for the first methyl substitution and a $28 \%$ attenuation with an additional methyl substitution.

V. Franck-Condon- and Ground-State Anion Calculations: Estimating the Energetics of Excited-State Evolution. Research efforts in our group focus on the study of the primary processes of excited-state relaxation in transition metal complexes. We discussed above how steric interactions modulate the degree of delocalization that is allowed in a ligand system following reduction, calculations designed to provide insight into the geometric and electronic structure of reduced ligands in long-lived ${ }^{3}$ MLCT states. We now address the question of how these states are formed in the initial stages of excited-state evolution following charge transfer from the metal. As was seen in the previous section, our calculations suggest that each of these ligands undergoes substantial geometric changes upon reduction, including a $\sim 40^{\circ}$ change in the inter-ring dihedral angle $\theta$ as well as a significant shortening of the central interring $\mathrm{C}-\mathrm{C}$ bond. These results have significant implications for understanding the Franck-Condon evolution of MLCT states involving the $\mathrm{dpb}$, dotb, and dmesb ligands. If we assume that MLCT transitions are vertical ones, then the ligand which is reduced initially has the geometry of the neutral (i.e., strongly canted). It then must relax to a more planar delocalized structure in the course of excited-state thermalization. We have estimated the energetics of this relaxation process by calculating $\Delta E_{\theta}$, the difference in energy between the reduced ligand in the geometry of the neutral (the Franck-Condon state) and the reduced ligand in a fully relaxed geometry. This is illustrated in the following schematic:

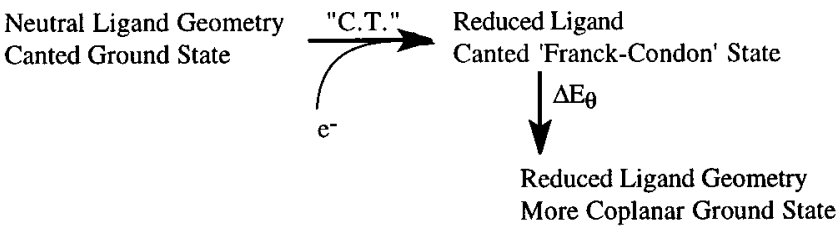

Reported here are the energetics of relaxation $\left(\Delta E_{\theta}\right)$ of the three model ligands as a function of both basis set as well as theoretical method. UHF methods were the starting point for this study, but due to spin contamination, other methods were attempted. The unrestricted DFT calculations show very little spin contamination for the doublet states considered here, and ROHF calculations remove this contamination altogether. Methods including treatment of electron correlation (DFT, MP2, and ROMP2) allow us to consider how correlation affects $\Delta E_{\theta}$. It is necessary at this point to discuss the methodology used for choosing the fixed geometry for the anion Franck-Condon state as well as the fixed geometry of the anion ground state for each of these molecules. As was discussed in section II, it is important to use correlated (non-DFT) methods for determining accurate geometries of systems where there is partial conjugation or loss of partial conjugation. Consequently, the fixed geometry of the Franck-Condon state for each of these three molecules was chosen from the MP2/6-31G(d) optimiza- 
tion of the corresponding ground-state neutral (Tables 2-4). The geometry used to describe the anion ground state for each of these molecules was also determined with correlated methods: in each case it is taken from the UMP2/6-31G(d) optimization of the corresponding anion. In this way, the method used to determine the Franck-Condon-state geometry and the ground-state geometry are consistent. It was of some concern that it might be more appropriate to use diffuse functions in the optimization of the anion ground-state geometry to be used for each molecule. Unfortunately, UMP2/6-31+G(d) optimization calculations were prohibitively expensive. Despite these concerns, a detailed comparison between the geometry of [4-phenylpyridine] ${ }^{-}$determined at the UHF/6-31G(d) level with one determined at the UHF/6-31+G(d) level shows very small and arguably insignificant absolute differences. For each bond length there is a less than $0.003 \AA$ change between geometries optimized with the two basis sets. For the molecules [4-(o-tolyl)pyridine $]^{-}$and [4-(2,6-dimethylphenyl)pyridine $^{-}$the geometry changes between the UHF/6-31G(d) optimized structures, and those done with UHF/6-31+G(d) are slightly larger (Table 6) but still appear to be insignificant. Finally, we need to address a concern about the method that was used to determine the geometry of the anion ground state for each of these molecules, specifically, in regards to the spin contamination seen in these UMP2/6-31G(d) optimizations. From Table 6 and an independent determination of $\Delta E_{\theta}$ for [4-(o-tolyl)pyridine $]^{-}$using DFT determined geometries (vide supra), we do not believe that slight admixture of higher lying quartet states is significantly changing the anion ground-state geometry for these three molecules.

Table 7 shows the Franck-Condon relaxation energetics for [4-phenylpyridine ${ }^{-}$. In this system, the molecule relaxes from a state in which the inter-ring dihedral angle $\theta$ is $44.6^{\circ}$ to one in which this angle $\theta$ is $0^{\circ}$. These data show several interesting trends. The first of these is that methods that take into account electron correlation effects generally calculate a smaller energy of relaxation (by several $\mathrm{kcal} / \mathrm{mol}$ ) than those methods that do not. The only exception to this trend is the spin-contaminated $\mathrm{MP} 2 / 6-31+\mathrm{G}(\mathrm{d})$ result. It is difficult to say at this point whether correlation effects are serving to stabilize the energy of the more canted Franck-Condon state, destabilize the energy of the more coplanar ground state, or both. We note here the success of the spin-contaminated UHF calculations in determining values of $\Delta E_{\theta}$ : these calculations agree reasonably with ROHF methods. It appears that in this case the error in the calculation of the absolute energy of these states is fortuitously subtracted away in the determination of $\Delta E_{\theta}$. The second trend worth noting is the subtle dependence of $\Delta E_{\theta}$ on the inclusion of diffuse functions. For both 3-21G(d) and 6-31G(d) basis sets, addition of diffuse functions serves to lower the calculated value of $\Delta E_{\theta}$ for all methods used. Again it is difficult to assign an absolute explanation for this trend; however, we expect that diffuse functions may play a more prominent role stabilizing the Franck-Condon state where electron delocalization is attenuated by the canted geometry. We note the subtle disagreement between the two DFT methods that were used. The SVWN functional consistently predicts a slightly larger value of $\Delta E_{\theta}$ than the B-LYP functional. Nonetheless, these two correlated methods always predict a lower value for $\Delta E_{\theta}$ than the uncorrelated methods. From these calculations, we believe the best estimate for $\Delta E_{\theta}$ comes from the correlated methods (ROMP2, UB-LYP, and USVWN) with the largest basis set $6-31+\mathrm{G}(\mathrm{d})$ and is therefore on the order of $4-7 \mathrm{kcal} /$ mol.
Table 8 shows the Franck-Condon relaxation energetics for [4-(o-tolyl)pyridine $]^{-}$. In this system, the molecule relaxes from a state in which the inter-ring dihedral angle $\theta$ is $59.6^{\circ}$ to one in which this angle $\theta$ is $28.6^{\circ}$. Here, the quality of the UHF calculations begins to become somewhat ambiguous as UHF always predicts a significantly larger $\Delta E_{\theta}$ than the other methods. As seen for [4-phenylpyridine] ${ }^{-}$, there is a decrease in the predicted value of $\Delta E_{\theta}$ when diffuse functions are included. Again, we suspect that this is because the severely canted Franck-Condon-state anions are stabilized preferentially with respect to the less canted and more delocalized anion ground states. Also as seen for [4-phenylpyridine ${ }^{-}$, there is some discrepancy between the two DFT methods, with UBLYP always predicting a lower $\Delta E_{\theta}$ than USVWN. We note that for all basis sets there is excellent agreement between the uncorrelated ROHF method and the correlated USVWN method. For the $6-31+\mathrm{G}(\mathrm{d})$ basis set, there is also good agreement between the uncorrelated ROHF method and the correlated ROMP2 method. From calculations with these several methods, the predicted value of $\Delta E_{\theta}$ for [4-(o-tolyl)pyridine] ${ }^{-}$lies between 4 and $7 \mathrm{kcal} / \mathrm{mol}$, remarkably similar to that seen for [4-phenylpyridine $]^{-}$.

As was discussed, there was some concern about using a spincontaminated calculation (UMP2/6-31G(d)) to determine the geometry used for the anion ground state in these calculations of $\Delta E_{\theta}$. To address these concerns, $\Delta E_{\theta}$ was determined independently in the present case using B-LYP methods, which show very little spin contamination when applied to these doublet anions (Tables 7-9). The geometry and energy of the anion ground state were taken from the UB-LYP/6-31G(d) optimization (Table 6: $\theta=26.7^{\circ}$ (average), $\mathrm{C}-\mathrm{C}=1.455 \AA$, -518.404664 hartrees, $\left.\left\langle S^{2}\right\rangle=0.7534\right)$. The geometry used for the Franck-Condon state was determined with a B-LYP/6-31G(d) optimization of the neutral, yielding a structure with $\theta=$ $52.305^{\circ}$ (average) and $\mathrm{C}-\mathrm{C}=1.498 \AA$. The corresponding Franck-Condon-state anion calculation (UB-LYP/6-31G(d)) yields an energy of -518.393522 hartrees with $\left\langle S^{2}\right\rangle=0.7521$. The calculated $\Delta E_{\theta}$ is therefore $6.992 \mathrm{kcal} / \mathrm{mol}$, in excellent agreement with the $\Delta E_{\theta}=6.408 \mathrm{kcal} / \mathrm{mol}$ determined with the UB-LYP/6-31G(d) method (Table 8) which used a geometry determined with a spin-contaminated method. Based on this result, we believe that spin contamination, as it applies to the ground-state anion geometry, is not a significant factor in the present analysis.

Table 9 shows the energetics of Franck-Condon-state relaxation for the last molecule in the series, [4-(2,6-dimethylphenyl)pyridine $]^{-}$. In this system, the molecule relaxes from a state in which the inter-ring dihedral angle $\theta$ is $90^{\circ}$ to one in which this angle $\theta$ is $42.6^{\circ}$. We note the reasonable agreement between the UHF, ROHF, and ROMP2 calculations of $\Delta E_{\theta}$, but treat it with some suspicion. In [4-phenylpyridine] ${ }^{-}$, error due to spin contamination may have fortuitously subtracted away in the calculation of $\Delta E_{\theta}$ (vide supra); however, we do not expect this to occur here. Spin contamination of the $90^{\circ}$ Franck-Condon state is relatively small $\left(\left\langle S^{2}\right\rangle \sim 0.8\right)$ compared to the anion ground state $\left(\left\langle S^{2}\right\rangle \sim 1.3\right)$. Had spin contamination of the $90^{\circ}$ Franck-Condon state been higher, we might expect to see a divergence between UHF and other methods as was seen in [4-(o-tolyl)pyridine $]^{-}$. It is seen in Table 9 that there is an absence of DFT calculations of $\Delta E_{\theta}$. While it is reasonable to calculate the energies of the anion ground state with these methods, it proved difficult to obtain energies of the $\theta=90^{\circ}$ Franck-Condon state. It is not clear to us at this time why these methods have trouble when the two ring $\pi$ systems are 
TABLE 7: Results from ab Initio Calculations of Singly Reduced 4-Phenylpyridine. Estimation of the Energetics of Franck-Condon-State Relaxation Using MP2 Geometries

\begin{tabular}{|c|c|c|c|}
\hline method/basis set & $\begin{array}{c}\text { energy (hartrees) and spin contamination } \\
\text { of ground state where } \\
\theta=0^{\circ} \text { and } \mathrm{C}-\mathrm{C}=1.431 \AA^{a}\end{array}$ & $\begin{array}{c}\text { energy (hartrees) and spin contamination } \\
\text { of Franck-Condon state where } \\
\theta=44.6^{\circ} \text { and } \mathrm{C}-\mathrm{C}=1.477 \AA^{b}\end{array}$ & $\begin{array}{c}\text { Franck-Condon-state } \\
\text { relaxation } \Delta E_{\theta^{\circ}}{ }^{c}(\mathrm{kcal} / \mathrm{mol})\end{array}$ \\
\hline $\mathrm{UHF} / 3-21 \mathrm{G}(\mathrm{d})$ & $\begin{array}{l}-473.537013 \\
\left\langle S^{2}\right\rangle=1.193\end{array}$ & $\begin{array}{l}-473.519897 \\
\left\langle S^{2}\right\rangle=1.247\end{array}$ & 10.7 \\
\hline ROHF/3-21G(d) & $\begin{array}{l}-473.519989 \\
\left\langle S^{2}\right\rangle=0.7500\end{array}$ & $\begin{array}{l}-473.504137 \\
\left\langle S^{2}\right\rangle=0.7500\end{array}$ & 9.95 \\
\hline USVWN/3-21G(d) & $\begin{array}{l}-474.001857 \\
\left\langle S^{2}\right\rangle=0.7513\end{array}$ & $\begin{array}{l}-473.989672 \\
\left\langle S^{2}\right\rangle=0.7511\end{array}$ & 7.65 \\
\hline UB-LYP/3-21G(d) & $\begin{array}{l}-476.467058 \\
\left\langle S^{2}\right\rangle=0.7531\end{array}$ & $\begin{array}{l}-476.457139 \\
\left\langle S^{2}\right\rangle=0.7523\end{array}$ & 6.22 \\
\hline $\mathrm{UHF} / 3-21+\mathrm{G}(\mathrm{d})$ & $\begin{array}{l}-473.605049 \\
\left\langle S^{2}\right\rangle=1.095\end{array}$ & $\begin{array}{l}-473.592001 \\
\left\langle S^{2}\right\rangle=1.163\end{array}$ & 8.19 \\
\hline $\mathrm{ROHF} / 3-21+\mathrm{G}(\mathrm{d})$ & $\begin{array}{l}-473.592067 \\
\left\langle S^{2}\right\rangle=0.7500\end{array}$ & $\begin{array}{l}-473.579987 \\
\left\langle S^{2}\right\rangle=0.7500\end{array}$ & 7.58 \\
\hline USVWN/3-21+G(d) & $\begin{array}{l}-474.073949 \\
\left\langle S^{2}\right\rangle=0.7511\end{array}$ & $\begin{array}{l}-474.063981 \\
\left\langle S^{2}\right\rangle=0.7511\end{array}$ & 6.26 \\
\hline UB-LYP/3-21+G(d) & $\begin{array}{l}-476.548298 \\
\left\langle S^{2}\right\rangle=0.7525\end{array}$ & $\begin{array}{l}-476.540776 \\
\left\langle S^{2}\right\rangle=0.7520\end{array}$ & 4.72 \\
\hline $\mathrm{UHF} / 6-31 \mathrm{G}(\mathrm{d})$ & $\begin{array}{l}-476.205605 \\
\left\langle S^{2}\right\rangle=1.149\end{array}$ & $\begin{array}{l}-476.187881 \\
\left\langle S^{2}\right\rangle=1.216\end{array}$ & 11.1 \\
\hline $\mathrm{ROHF} / 6-31 \mathrm{G}(\mathrm{d})$ & $\begin{array}{l}-476.189365 \\
\left\langle S^{2}\right\rangle=0.7500\end{array}$ & $\begin{array}{l}-476.172659 \\
\left\langle S^{2}\right\rangle=0.7500\end{array}$ & 10.5 \\
\hline USVWN/6-31G(d) & $\begin{array}{l}-476.623054 \\
\left\langle S^{2}\right\rangle=0.7513\end{array}$ & $\begin{array}{l}-476.610090 \\
\left\langle S^{2}\right\rangle=0.7511\end{array}$ & 8.14 \\
\hline UB-LYP/6-31G(d) & $\begin{array}{l}-479.115380 \\
\left\langle S^{2}\right\rangle=0.7532\end{array}$ & $\begin{array}{l}-479.104995 \\
\left\langle S^{2}\right\rangle=0.7524\end{array}$ & 6.52 \\
\hline $\mathrm{UHF} / 6-31+\mathrm{G}(\mathrm{d})$ & $\begin{array}{l}-476.232817 \\
\left\langle S^{2}\right\rangle=1.090\end{array}$ & $\begin{array}{l}-476.217832 \\
\left\langle S^{2}\right\rangle=1.182\end{array}$ & 9.40 \\
\hline MP2/6-31+G(d) & $\begin{array}{l}-477.782907 \\
\left\langle S^{2}\right\rangle=0.9852\end{array}$ & $\begin{array}{l}-477.767786 \\
\left\langle S^{2}\right\rangle=1.176\end{array}$ & 9.49 \\
\hline $\mathrm{ROHF} / 6-31+\mathrm{G}(\mathrm{d})$ & $\begin{array}{l}-476.219539 \\
\left\langle S^{2}\right\rangle=0.7500\end{array}$ & $\begin{array}{l}-476.205583 \\
\left\langle S^{2}\right\rangle=0.7500\end{array}$ & 8.76 \\
\hline ROMP2/6-31+G(d) & $\begin{array}{l}-477.809022 \\
\left\langle S^{2}\right\rangle=0.7500\end{array}$ & $\begin{array}{l}-477.802382 \\
\left\langle S^{2}\right\rangle=0.7500\end{array}$ & 4.17 \\
\hline USVWN/6-31+G(d) & $\begin{array}{l}-476.657072 \\
\left\langle S^{2}\right\rangle=0.7512\end{array}$ & $\begin{array}{l}-476.645526 \\
\left\langle S^{2}\right\rangle=0.7511\end{array}$ & 7.25 \\
\hline UB-LYP/6-31+G(d) & $\begin{array}{l}-479.156842 \\
\left\langle S^{2}\right\rangle=0.7527\end{array}$ & $\begin{array}{l}-479.147959 \\
\left\langle S^{2}\right\rangle=0.7510\end{array}$ & 5.57 \\
\hline
\end{tabular}

${ }^{a}$ Molecular geometry of ground-state anion chosen from UMP2/6-31G(d) geometry optimization of (4-phenylpyridine) ${ }^{-} .{ }^{b}$ Molecular geometry of Franck-Condon state chosen from MP2/6-31G(d) geometry optimization of neutral 4-phenylpyridine. ${ }^{c} \Delta E_{\theta^{\circ}}$ refers to the difference in energy between the Franck-Condon state and the ground state.

orthogonal. Our working assumption is that the extra electron hops between rings, resulting in an unfavorable oscillation of the energy. The remaining methods for predicting $\Delta E_{\theta}$ are ROHF and ROMP2. These show a strong basis set dependence, in agreement with the previous two molecules, where the addition of diffuse functions serves to lower the calculated value of $\Delta E_{\theta}$. In this molecule, where the Franck-Condon state is severely canted $\left(\theta=90^{\circ}\right)$, the effect of diffuse functions is the most pronounced. Here, in contrast to the previous two molecules, the correlated method (ROMP2) predicts a slightly larger $\Delta E_{\theta}$ than the uncorrelated one (ROHF). In the previous two molecules there was reasonable agreement between the ROMP2/6-31+G(d), USVWN/6-31+G(d), and UB-LYP /6$31+\mathrm{G}(\mathrm{d})$ calculations of $\Delta E_{\theta}$. We therefore take the ROMP2/ 6-31+G(d) calculation of $\Delta E_{\theta}=5.80 \mathrm{kcal} / \mathrm{mol}$ for [4- $(2,6-$ dimethyl-phenyl)pyridine $]^{-}$as our most accurate estimate of these energetics.

The calculated $\Delta E_{\theta}$ for [4-(2,6-dimethylphenyl)pyridine $]^{-}$is approximately the same as that seen for [4-(o-tolyl)pyridine $]^{-}$ and [4-phenylpyridine $]^{-}$and, as such, establishes the interesting observation that the thermodynamic driving force for FranckCondon-state relaxation remains relatively constant even as steric bulk is added to these systems. The exact physical explanation of this observation is not obvious at this point. We note that the change in the dihedral angle $\theta$ concomitant with the Franck-Condon relaxation process is not constant across this series of molecules, nor does it follow any particular trend: $\Delta \theta=44.6^{\circ}$ for [4-phenylpyridine] ${ }^{-}, \Delta \theta=31.0^{\circ}$ for [4-(o-tolyl)pyridine $]^{-}$, and $\Delta \theta=47.4^{\circ}$ for [4-(2,6-dimethylphenyl)pyridine $]^{-}$. However, what is constant across this series of molecules is the change in the inter-ring $\mathrm{C}-\mathrm{C}$ bond length during the Franck-Condon-state relaxation process: $\Delta(\mathrm{C}-\mathrm{C})$ $=0.046 \AA$ for [4-phenylpyridine] ${ }^{-}, \Delta(\mathrm{C}-\mathrm{C})=0.047 \AA$ for [4-(o-tolyl)pyridine $]^{-}$, and $\Delta(\mathrm{C}-\mathrm{C})=0.047 \AA$ for [4-(2,6dimethylphenyl)pyridine $]^{-}$. The change in inter-ring bond length may therefore be a sensitive indicator of the amount of stabilization due to delocalization that is gained in the FranckCondon relaxation of these molecules.

\section{Concluding Comments}

There are two principal conclusions to be drawn directly from the calculations on aryl-substituted pyridines described above. The first is that one-electron reduction of these ligands results in significant changes in geometry with regard to bond distances and, in particular, the torsional angle between the pyridyl and phenyl rings. Specifically, in all three cases the reduced ligand exhibits a strong preference for a more planar structure relative to the neutral species. Second, the effective driving force for 
TABLE 8: Results from ab Initio Calculations of Frozen Singly Reduced 4-(o-Tolyl)pyridine. Estimation of the Energetics of Franck-Condon-State Relaxation Using MP2 Geometries

\begin{tabular}{|c|c|c|c|}
\hline method/basis set & $\begin{array}{c}\text { energy (hartrees) and spin contamination } \\
\text { of ground state where } \\
\theta=28.6^{\circ} \text { (av) and } \mathrm{C}-\mathrm{C}=1.434 \AA^{a}\end{array}$ & $\begin{array}{c}\text { energy (hartrees) and spin contamination } \\
\text { of Franck-Condon state where } \\
\theta=59.6^{\circ}(\mathrm{av}) \text { and } \mathrm{C}-\mathrm{C}=1.481 \AA^{b}\end{array}$ & $\begin{array}{c}\text { Franck-Condon-state } \\
\text { relaxation } \Delta E_{\theta^{\circ}}{ }^{c}(\mathrm{kcal} / \mathrm{mol})\end{array}$ \\
\hline $\mathrm{UHF} / 3-21 \mathrm{G}(\mathrm{d})$ & $\begin{array}{l}-512.345954 \\
\left\langle S^{2}\right\rangle=1.204\end{array}$ & $\begin{array}{l}-512.322266 \\
\left\langle S^{2}\right\rangle=0.9495\end{array}$ & 14.9 \\
\hline $\mathrm{ROHF} / 3-21 \mathrm{G}(\mathrm{d})$ & $\begin{array}{l}-512.329029 \\
\left\langle S^{2}\right\rangle=0.7500\end{array}$ & $\begin{array}{l}-512.315317 \\
\left\langle S^{2}\right\rangle=0.7500\end{array}$ & 8.60 \\
\hline USVWN/3-21G(d) & $\begin{array}{l}-512.885098 \\
\left\langle S^{2}\right\rangle=0.7513\end{array}$ & $\begin{array}{l}-512.871767 \\
\left\langle S^{2}\right\rangle=0.7510\end{array}$ & 8.37 \\
\hline UB-LYP/3-21G(d) & $\begin{array}{l}-515.533573 \\
\left\langle S^{2}\right\rangle=0.7528\end{array}$ & $\begin{array}{l}-515.524401 \\
\left\langle S^{2}\right\rangle=0.7521\end{array}$ & 5.76 \\
\hline $\mathrm{UHF} / 3-21+\mathrm{G}(\mathrm{d})$ & $\begin{array}{l}-512.415503 \\
\left\langle S^{2}\right\rangle=1.120\end{array}$ & $\begin{array}{l}-512.401477 \\
\left\langle S^{2}\right\rangle=0.8709\end{array}$ & 8.80 \\
\hline $\mathrm{ROHF} / 3-21+\mathrm{G}(\mathrm{d})$ & $\begin{array}{l}-512.401913 \\
\left\langle S^{2}\right\rangle=0.7500\end{array}$ & $\begin{array}{l}-512.395005 \\
\left\langle S^{2}\right\rangle=0.7500\end{array}$ & 4.34 \\
\hline USVWN/3-21+G(d) & $\begin{array}{l}-512.959550 \\
\left\langle S^{2}\right\rangle=0.7511\end{array}$ & $\begin{array}{l}-512.950608 \\
\left\langle S^{2}\right\rangle=0.7509\end{array}$ & 5.61 \\
\hline UB-LYP/3-21+G(d) & $\begin{array}{l}-515.616991 \\
\left\langle S^{2}\right\rangle=0.7524\end{array}$ & $\begin{array}{l}-515.612664 \\
\left\langle S^{2}\right\rangle=0.7518\end{array}$ & 2.72 \\
\hline $\mathrm{UHF} / 6-31 \mathrm{G}(\mathrm{d})$ & $\begin{array}{l}-515.230736 \\
\left\langle S^{2}\right\rangle=1.164\end{array}$ & $\begin{array}{l}-515.206914 \\
\left\langle S^{2}\right\rangle=0.9812\end{array}$ & 15.0 \\
\hline $\mathrm{ROHF} / 6-31 \mathrm{G}(\mathrm{d})$ & $\begin{array}{l}-515.214503 \\
\left\langle S^{2}\right\rangle=0.7500\end{array}$ & $\begin{array}{l}-515.199595 \\
\left\langle S^{2}\right\rangle=0.7500\end{array}$ & 9.36 \\
\hline USVWN/6-31G(d) & $\begin{array}{l}-515.717566 \\
\left\langle S^{2}\right\rangle=0.7512\end{array}$ & $\begin{array}{l}-515.702969 \\
\left\langle S^{2}\right\rangle=0.7510\end{array}$ & 9.16 \\
\hline UB-LYP/6-31G(d) & $\begin{array}{l}-518.396051 \\
\left\langle S^{2}\right\rangle=0.7529\end{array}$ & $\begin{array}{l}-518.385839 \\
\left\langle S^{2}\right\rangle=0.7522\end{array}$ & 6.41 \\
\hline $\mathrm{UHF} / 6-31+\mathrm{G}(\mathrm{d})$ & $\begin{array}{l}-515.256968 \\
\left\langle S^{2}\right\rangle=1.117\end{array}$ & $\begin{array}{l}-515.239139 \\
\left\langle S^{2}\right\rangle=0.9468\end{array}$ & 11.2 \\
\hline $\mathrm{ROHF} / 6-31+\mathrm{G}(\mathrm{d})$ & $\begin{array}{l}-515.243041 \\
\left\langle S^{2}\right\rangle=0.7500\end{array}$ & $\begin{array}{l}-515.232470 \\
\left\langle S^{2}\right\rangle=0.7500\end{array}$ & 6.63 \\
\hline $\mathrm{ROMP} 2 / 6-31+\mathrm{G}(\mathrm{d})$ & $\begin{array}{l}-516.976474 \\
\left\langle S^{2}\right\rangle=0.7500\end{array}$ & $\begin{array}{l}-516.967826 \\
\left\langle S^{2}\right\rangle=0.7500\end{array}$ & 5.43 \\
\hline USVWN/6-31+G(d) & $\begin{array}{l}-515.751170 \\
\left\langle S^{2}\right\rangle=0.7511\end{array}$ & $\begin{array}{l}-515.739408 \\
\left\langle S^{2}\right\rangle=0.7509\end{array}$ & 7.38 \\
\hline UB-LYP/6-31+G(d) & $\begin{array}{l}-518.436700 \\
\left\langle S^{2}\right\rangle=0.7526\end{array}$ & $\begin{array}{l}-518.429543 \\
\left\langle S^{2}\right\rangle=0.7520\end{array}$ & 4.49 \\
\hline
\end{tabular}

${ }^{a}$ Molecular geometry of ground-state anion chosen from UMP2/6-31G(d) geometry optimization of (4-(o-tolyl)pyridine $)^{-} .{ }^{b}$ Molecular geometry of Franck-Condon state chosen from MP2/6-31G(d) geometry optimization of neutral 4-(o-tolyl)pyridine. ${ }^{c} \Delta E_{\theta^{\circ}}$ refers to the difference in energy between the Franck-Condon state and the ground state.

reorganization from the neutral "Franck-Condon" geometry to the fully relaxed anion is approximately the same as the steric bulk of the aryl substituent is increased. Although these ligands represent simplified models of the $\mathrm{Ru}^{\mathrm{II}}$ bipyridyl complexes that are our primary interest, we believe that we can use the information gleaned through these calculations in at least a qualitative if not semiquantitative fashion for developing a physical picture of the events that characterize the dynamics of MLCT excited-state evolution in the corresponding arylsubstituted bipyridyl complexes. In this context, these calculations provide us with a detailed model for how to think about the evolution of both geometric structure and the wave function itself, as well as possible relative rates of Franck-Condon-state relaxation following photoexcitation in complexes containing these ligands.

The most obvious difference between the Franck-Condon state and the fully relaxed anion is the change in the angle between the pyridyl and aryl rings. Based on this, we expect that excited-state thermalization following photoexcitation will be characterized in all three cases (i.e., dpb, dotb, and dmesb complexes) by rotation of the peripheral aryl rings of ca. $40^{\circ}$. This represents a significant change in molecular geometry and underscores the vibronic nature of the initial stages of excitedstate relaxation in these compounds: the evolution of the wave function is intimately dependent on this change in geometry taking place (vide infra). It is widely accepted that vibronic coupling in the ground-state recovery process in Ru-bipyridyl complexes (i.e., ${ }^{3} \mathrm{MLCT} \rightarrow{ }^{1} \mathrm{~A}_{1}$ relaxation) occurs primarily through the aromatic $\mathrm{C}-\mathrm{C}$ stretches of the bipyridyl rings. ${ }^{26} \mathrm{In}$ the case of the dpb, dotb, and dmesb complexes, FranckCondon-state evolution is clearly going to be strongly influenced by the inter-ring torsional mode. Although it is not possible to identify such a low-frequency mode in the structured emission spectra of these compounds, ${ }^{27}$ these results suggest coupling to different nuclear coordinates for the ${ }^{1}$ MLCT $\rightarrow{ }^{3}$ MLCT and ${ }^{3} \mathrm{MLCT} \rightarrow{ }^{1} \mathrm{~A}_{1}$ relaxation processes. These observations thus give an indication of the potentially complex nature of wave packet motion on the excited-state potential energy surface of these complexes in terms of coupling to multiple modes in the course of excited-state relaxation. These results also provide important new insights into the details of the initial stages of the excited-state evolution of this class of molecules, in that it represents a case in which the vibronic nature of the potential surface can be defined from the moment of photon absorption through recovery of the ground state. Our results also tie into other studies such as those by Miller ${ }^{28}$ and McLendon, ${ }^{29}$ in which torsional modes have been implicated as playing an important role in electron-transfer reactions.

It has been shown both from the calculations presented here and from our previous study that the extent to which coplanarity of the phenyl and pyridyl fragments can be achieved in these systems is determined largely by steric factors. This provided 
TABLE 9: Results from ab Initio Calculations of Singly Reduced 4-(2,6-Dimethylphenyl)pyridine. Estimation of the Energetics of Franck-Condon-State Relaxation Using MP2 Geometries

\begin{tabular}{|c|c|c|c|}
\hline method/basis set & $\begin{array}{l}\text { energy (hartrees) and spin contamination } \\
\text { of ground state where } \\
\theta=42.6^{\circ} \text { and } \mathrm{C}-\mathrm{C}=1.438 \AA^{a}\end{array}$ & $\begin{array}{l}\text { energy (hartrees) and spin contamination } \\
\text { of Franck-Condon state where } \\
\theta=90^{\circ} \text { and } \mathrm{C}-\mathrm{C}=1.484 \AA^{b}\end{array}$ & $\begin{array}{c}\text { Franck-Condon-state } \\
\text { relaxation } \Delta E_{\theta^{\circ}}{ }^{c}(\mathrm{kcal} / \mathrm{mol})\end{array}$ \\
\hline $\mathrm{UHF} / 3-21 \mathrm{G}(\mathrm{d})$ & $\begin{array}{l}-551.156290 \\
\left\langle S^{2}\right\rangle=1.215\end{array}$ & $\begin{array}{l}-551.139146 \\
\left\langle S^{2}\right\rangle=0.8202\end{array}$ & 10.8 \\
\hline ROHF/3-21G(d) & $\begin{array}{l}-551.139966 \\
\left\langle S^{2}\right\rangle=0.7500\end{array}$ & $\begin{array}{l}-551.128210 \\
\left\langle S^{2}\right\rangle=0.7500\end{array}$ & 7.38 \\
\hline ROMP2/3-21G(d) & $\begin{array}{l}-552.409044 \\
\left\langle S^{2}\right\rangle=0.7500\end{array}$ & $\begin{array}{l}-552.391893 \\
\left\langle S^{2}\right\rangle=0.7500\end{array}$ & 10.8 \\
\hline $\mathrm{UHF} / 3-21+\mathrm{G}(\mathrm{d})$ & $\begin{array}{l}-551.228937 \\
\left\langle S^{2}\right\rangle=1.141\end{array}$ & $\begin{array}{l}-551.223160 \\
\left\langle S^{2}\right\rangle=0.8383\end{array}$ & 3.63 \\
\hline $\mathrm{ROHF} / 3-21+\mathrm{G}(\mathrm{d})$ & $\begin{array}{l}-551.215460 \\
\left\langle S^{2}\right\rangle=0.7500\end{array}$ & $\begin{array}{l}-551.213974 \\
\left\langle S^{2}\right\rangle=0.7500\end{array}$ & 0.933 \\
\hline ROMP2/3-21+G(d) & $\begin{array}{l}-552.522431 \\
\left\langle S^{2}\right\rangle=0.7500\end{array}$ & $\begin{array}{l}-552.519974 \\
\left\langle S^{2}\right\rangle=0.7500\end{array}$ & 1.54 \\
\hline $\mathrm{UHF} / 6-31 \mathrm{G}(\mathrm{d})$ & $\begin{array}{l}-554.256150 \\
\left\langle S^{2}\right\rangle=1.178\end{array}$ & $\begin{array}{l}-554.239394 \\
\left\langle S^{2}\right\rangle=0.8586\end{array}$ & 10.5 \\
\hline ROHF/6-31G(d) & $\begin{array}{l}-554.240478 \\
\left\langle S^{2}\right\rangle=0.7500\end{array}$ & $\begin{array}{l}-554.227829 \\
\left\langle S^{2}\right\rangle=0.7500\end{array}$ & 7.94 \\
\hline ROMP2/6-31G(d) & $\begin{array}{l}-556.089683 \\
\left\langle S^{2}\right\rangle=0.7500\end{array}$ & $\begin{array}{l}-556.070087 \\
\left\langle S^{2}\right\rangle=0.7500\end{array}$ & 12.3 \\
\hline $\mathrm{UHF} / 6-31+\mathrm{G}(\mathrm{d})$ & $\begin{array}{l}-554.281945 \\
\left\langle S^{2}\right\rangle=1.141\end{array}$ & $\begin{array}{l}-554.272027 \\
\left\langle S^{2}\right\rangle=0.8468\end{array}$ & 6.22 \\
\hline ROHF/6-31+G(d) & $\begin{array}{l}-554.268113 \\
\left\langle S^{2}\right\rangle=0.7500\end{array}$ & $\begin{array}{l}-554.262500 \\
\left\langle S^{2}\right\rangle=0.7500\end{array}$ & 3.52 \\
\hline ROMP2/6-31+G(d) & $\begin{array}{l}-556.143595 \\
\left\langle S^{2}\right\rangle=0.7500\end{array}$ & $\begin{array}{l}-556.134351 \\
\left\langle S^{2}\right\rangle=0.7500\end{array}$ & 5.80 \\
\hline
\end{tabular}

${ }^{a}$ Molecular geometry of ground-state anion chosen from UMP2/6-31G(d) geometry optimization of (4-(2,6-dimethylphenyl)pyridine) ${ }^{-} .{ }^{b}$ Molecular geometry of Franck-Condon state chosen from MP2/6-31G(d) geometry optimization of neutral 4-(2,6-dimethylphenyl)pyridine. ${ }^{c} \Delta E_{\theta^{\circ}}$ refers to the difference in energy between the Franck-Condon state and the ground state.

a means for controlling intraligand electron delocalization through synthetic means as demonstrated in our earlier work. ${ }^{7}$ As mentioned above, the bipyridyl complexes represent a situation in which electronic relaxation (i.e., intraligand electron delocalization) is intimately coupled with structural reorganization, and vice versa. The time scale for formation of the ${ }^{3} \mathrm{MLCT}$ state in these systems is on the order of $100 \mathrm{fs},{ }^{30}$ placing it on the same approximate time scale as the inertial response of many common solvents such as $\mathrm{CH}_{3} \mathrm{CN}$. It seems reasonable, then, to expect that intermolecular sterics such as dielectric friction from the surrounding solvent will play an important role in dictating relaxation dynamics for the ${ }^{1}$ MLCT $\rightarrow{ }^{3}$ MLCT Franck-Condon-state evolution in these compounds. One can even think of taking this notion a step further and attempt to exploit such solvent-solute interactions to examine the interplay between electronic and geometric factors in the course of excited-state relaxation.

Our calculations also point toward an intriguing notion concerning the evolution of the wave function itself. This can be gleaned from a comparison of the distribution of the single transferred electron (i.e., the MLCT-state electron in the $\pi^{*}$ system) within the ligands in the Franck-Condon state with its distribution following electronic and structural relaxation. This electron density can be gauged by the SOMO of each system in its Franck-Condon and fully relaxed state. The fully relaxed anions have been previously discussed and are illustrated in Figure 4; the corresponding orbitals from the Franck-Condon states of all three ligands are shown in Figure $6 .{ }^{31}$ For the purposes of this discussion, we shall focus only on the 4-(2,6dimethylphenyl)pyridine case, which shows the most dramatic effect: this is illustrated in Figure 7.32 The important point to note is the amplitude of the wave function on the peripheral aryl ring relative to that on the pyridyl ring. Following photoexcitation (i.e., reduction) but prior to excited-state relaxation, nearly all of the electron density associated with the extra electron is localized on the pyridyl ring. Now, as the system begins to move away from the Franck-Condon region in the course of excited-state thermalization (i.e., rotation through $\theta$ toward $\sim 45^{\circ}$ ), the orthogonality between the two rings is broken and overlap between the $\pi$ systems begins to increase as a function of time. As this occurs, electron density flows out of the pyridyl ring and onto the aryl substituent. This shift in electron density concomitant with ring rotation should have an experimentally observable effect on the spectroscopic properties of the system. For example, femtosecond timeresolved infrared spectroscopy could reveal the dynamics of this process by probing changes in ring vibrations as a function of time. In an approximate sense, our model would predict that, at $t=0$, two sets of bands would be observed: one at low frequency corresponding to the highly reduced pyridyl fragment, the other to the relatively unperturbed aryl substituent. As the system evolves in time, these two bands should move toward each other in frequency as the electron density partially shifts to the aryl ring. Other spectroscopic features, such as absorption cross sections, are also likely to be affected. The net result is a series of experiments that will allow us to observe in real time the onset of this extended intraligand electron delocalization. We believe this is a very exciting prospect, made possible due to the unique vibronic nature of the present system. Experiments along these lines are currently under way.

Finally, the Franck-Condon-state relaxation $\left(\Delta E_{\theta}\right)$ described above yields effective potential energy surfaces for excited-state thermalization that we can use to predict the relative rates of ${ }^{1} \mathrm{MLCT} \rightarrow{ }^{3} \mathrm{MLCT}$ relaxation across this series of compounds. Assuming that the energy difference between the FranckCondon state and fully relaxed anion is representative of the free energy for the relaxation process, the value of ca. $5 \mathrm{kcal} /$ mol that was obtained for all three ligands suggests that the 

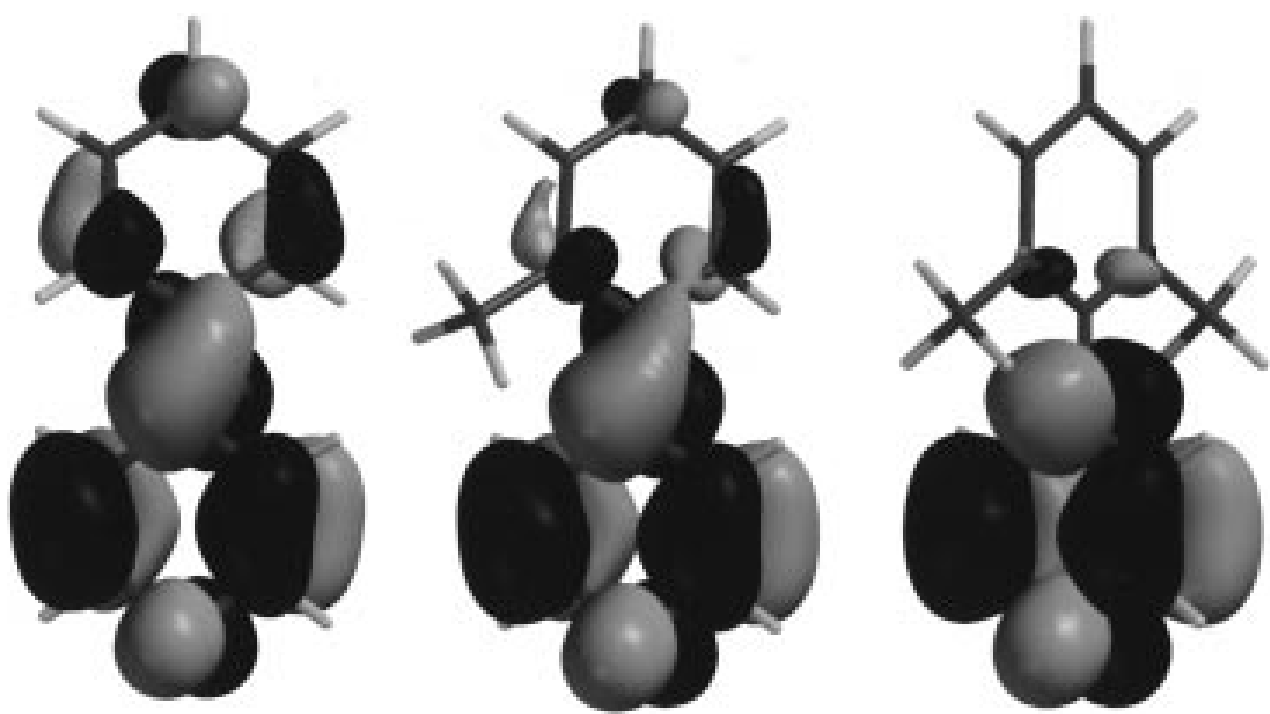

Figure 6. Singly occupied molecular orbitals (SOMOs) for [4-phenylpyridine $]^{-}$(left), [4-(o-tolyl)pyridine) $]^{-}$(center), and [4-(2,6-dimethylphenyl)pyridine $]^{-}$(right) in their respective Franck-Condon states.
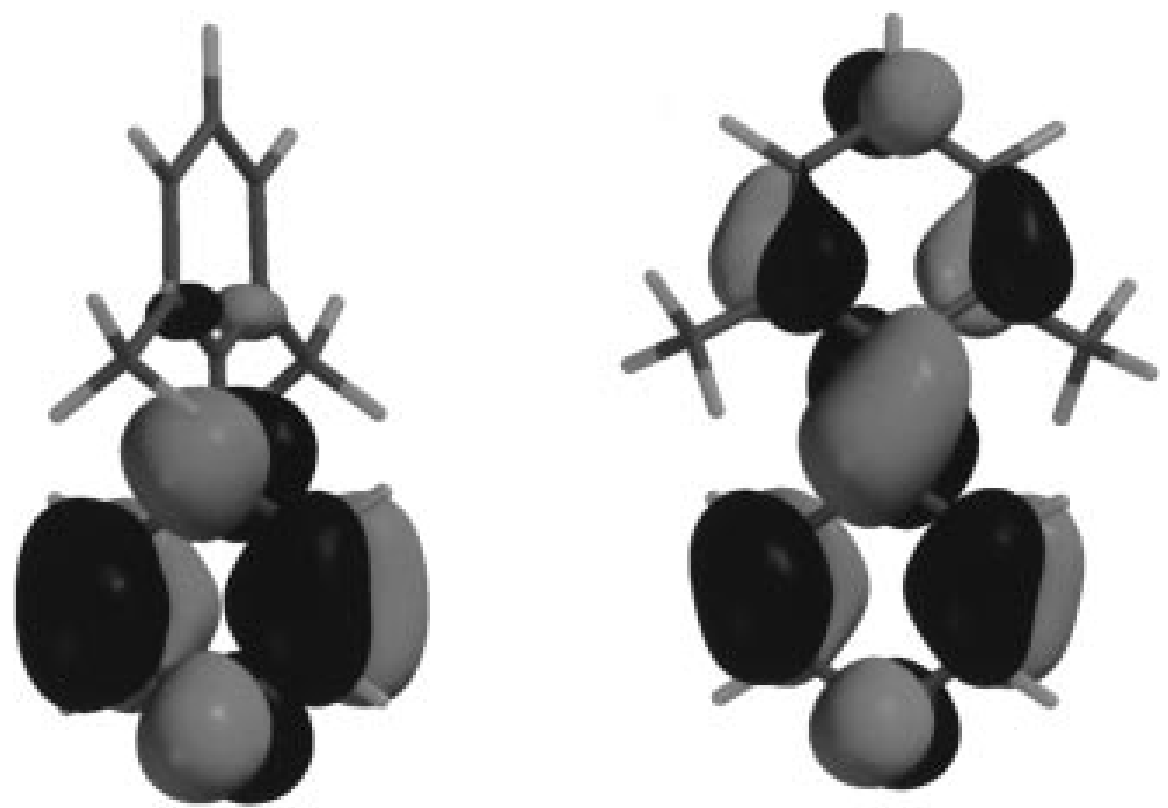

Figure 7. Singly occupied molecular orbitals (SOMOs) for [4-(2,6-dimethylphenyl)pyridine $]^{-}$in its Franck-Condon state (left) and fully relaxed form (right). Excited-state relaxation in these systems therefore corresponds approximately to an evolution of the wave function from the description on the left to the one shown on the right. See text for further details.

time scale for ring rotation will be approximately the same for $\mathrm{dpb}$, dotb, and dmesb complexes. This is a somewhat counterintuitive prediction, in that one might have expected that the more sterically encumbered system (i.e., 4-(2,6-dimethylphenyl)pyridine) would have a much smaller driving force for achieving a more planar configuration relative to, for example, the fully relaxed [4-phenylpyridine] ${ }^{-}$. However, our calculations suggest that the steepness of the free energy surface for the ${ }^{1}$ MLCT $\rightarrow$ ${ }^{3}$ MLCT relaxation process is quite comparable for all three cases. Of course, other factors will need to be considered in order to interpret results from femtosecond time scale experiments, but these calculations have given us a useful working model for understanding the ultrafast dynamics of MLCT excited states in this class of compounds.

Acknowledgment. This work utilized the HP/CONVEX Exemplar SPP-2000 at the National Center for Supercomputing Applications, University of Illinois at Urbana-Champaign, as well as the Cray C90 at the San Diego Supercomputer Center.
The authors wish to thank Professors Martin Head-Gordon and Mark Gordon for helpful discussions and Professor Jeff Long for assistance with the X-ray crystallography. This work was supported by the Division of Chemical Sciences, Office of Basic Energy Sciences, Office of Energy Research, U.S. Department of Energy, Grant No. DE-FG03-96ER14665.

Supporting Information Available: Full crystallographic details, positional parameters, bond distances and angles, and thermal displacement parameters for 4,4'-diphenyl-2,2'-bipyridine (dpb), 4,4'-di-o-tolyl-2,2'-bipyridine (dotb), and 4,4'dimesityl-2,2'-bipyridine (dmesb) (14 pages). See any current masthead page for ordering and Internet access instructions.

\section{References and Notes}

(1) For a general reference on the photophysics and photochemistry of transition metal complexes, see: Roundhill, D. M. Photochemistry and Photophysics of Metal Complexes; Plenum Press: New York, 1994.

(2) See, for example: (a) Dibilio, A. J.; Hill, M. G.; Bonander, N.; Karlsson, B. G.; Villahermosa, R. M.; Malmstrom, B. G.; Winkler, J. R.; 
Gray, H. B. J. Am. Chem. Soc. 1997, 119, 9921. (b) Winkler, J. R.; Gray, H. B. J. Biol. Inorg. Chem. 1997, 2, 399. (c) Gray, H. B.; Winkler, J. R. Annu. Rev. Biochem. 1996, 65, 537, and references therein. (d) Kelley, S. O.; Holmlin, R. E.; Stemp, E. D. A.; Barton, J. K. J. Am. Chem. Soc. 1997 119, 9861. (e) Kelly, J. M.; Feeny, M. M.; Jacquet, L.; KirschDeMesmaeker, A.; Lecomte, J. P. Pure Appl. Chem. 1997, 69, 767. (f) Olson, E. J. C.; Hu, D. H.; Hormann, A.; Barbara, P. F. J. Phys. Chem. A 1997, 101, 299. (g) Meade, T. J.; Kayyem, J. F. Angew. Chem., Int. Ed. Engl. 1995, 34, 352.

(3) (a) Hannappel, T.; Burfeindt, B.; Storck, W.; Willig, F. J. Phys. Chem. B 1997, 101, 6799. (b) Tachibana, Y.; Moser, J. E.; Grätzel, M.; Klug, D. R.; Durrant, J. R. J. Phys. Chem. 1996, 100, 20056. (c) Argazzi, R.; Bignozzi, C. A.; Heimer, T. A.; Castellano, F. N.; Meyer, G. J. Inorg. Chem. 1994, 33, 5741. (d) Argazzi, R.; Bignozzi, C. A.; Heimer, T. A.; Castellano, F. N.; Meyer, G. J. J. Phys. Chem. B 1997, 101, 2591. (e) Hagfeldt, A.; Grätzel, M. Chem. Rev. 1995, 95, 49, and references therein.

(4) Juris, A.; Baragelletti, S.; Campagna, S.; Balzani, V.; Belser, P.; von Zelewski, A. Coord. Chem. Rev. 1988, 84, 85.

(5) (a) Casper, J. V.; Meyer, T. J. J. Phys. Chem. 1983, 87, 952. (b) Barqawi, K. R.; Murtaza, Z.; Meyer, T. J. J. Phys. Chem. 1991, 95, 47. (c) Claude, J. P.; Meyer, T. J. J. Phys. Chem. 1995, 99, 51, and references therein. See also ref 4.

(6) (a) Freed, K. F.; Jortner, J. J. Chem. Phys. 1970, 62, 72. (b) Engleman, R.; Jortner, J. Mol. Phys. 1970, 18, 145. (c) Jortner, J. J. Chem. Phys. 1976, 64, 4860. (d) Jortner, J.; Bixon, M. Ber. Bunsen-Ges. Phys. Chem. 1995, 99, 296. (e) Hopfield, J. J. Proc. Natl. Acad. Sci. U.S.A. 1974 71,3640 .

(7) Damrauer, N. H.; Boussie, T. R.; Devenney, M.; McCusker, J. K. J. Am. Chem. Soc. 1997, 119, 8253.

(8) Frisch, M. J.; Trucks, G. W.; Head-Gordon, M.; Gill, P. M. W.; Wong, M. W.; Foresman, J. B.; Johnson, B. G.; Schlegel, H. B.; Robb, M. A.; Replogle, E. S.; Gomperts, R.; Andres, J. L.; Raghavachari, K.; Binkley, J. S.; Gonzalez, C.; Martin, R. L.; Fox, D. J.; Defrees, D. J.; Baker, J.; Stewart, J. J. P.; Pople, J. A. Gaussian 92, Revision G.2; Gaussian, Inc.: Pittsburgh, PA, 1992

(9) Frisch, M. J.; Trucks, G. W.; Schlegel, H. B.; Gill, P. M. W.; Johnson, B. G.; Robb, M. A.; Cheeseman, J. R.; Keith, T. A.; Petersson, G. A.; Montgomery, J. A.; Raghavachari, K.; Al-Laham, M. A.; Zakrzewski, V. G.; Ortiz, J. V.; Foresman, J. B.; Cioslowski, J.; Stefanov, B. B.; Nanayakkara, A.; Challacombe, M.; Peng, C. Y.; Ayala, P. Y.; Chen, W.; Wong, M. W.; Andres, J. L.; Replogle, E. S.; Gomperts, R.; Martin, R. L.; Fox, D. J.; Binkley, J. S.; Defrees, D. J.;.; Baker, J.; Stewart, J. J. P.; HeadGordon, M.; Gonzalez, C.; Pople, J. A. Gaussian 94, Revision C.2; Gaussian, Inc.: Pittsburgh, PA, 1995.

(10) Møller, C.; Plesset, M. S. Phys. Rev. 1934, 46, 618

(11) (a) Slater, J. C. Quantum Theory of Molecules and Solids; McGrawHill: New York, 1974; Vol. 4. (b) Vosko, S. H.; Wilk, L.; Nusair, M. Can. J. Phys. 1980, 58, 1200.

(12) (a) Becke, A. D. Phys. Rev. A 1988, 38, 3098. (b) Lee, C.; Yang, W.; Parr, R. G. Phys. Rev. B 1988, 37, 785. (c) Miehlich, B.; Savin, A.; Stoll, H.; Preuss, H. Chem Phys. Lett. 1989, 157, 200.

(13) teXan: Crystal Structure Analysis Package; Molecular Structure Corporation, 1985 and 1992.

(14) (a) Phifer, C. C.; McMillin, D. R. Inorg. Chem. 1986, 25, 1329. (b) Strouse, G. F.; Schoonover, J. R.; Duesing, R.; Boyde, S.; Jones, W E.; Meyer, T. J. Inorg. Chem. 1995, 34, 473. (c) Hammarström, L.; Barigelletti, F.; Flamigni, L.; Indelli, M. T.; Armaroli, N.; Calogero, G.; Guardigli, M.; Sour, A.; Collin, J.-P.; Sauvage, J.-P. J. Phys. Chem. A 1997 101,9061 .
(15) Treadway, J. A.; Loeb, B.; Lopez, R.; Anderson, P. A.; Keene, F. R.; Meyer, T. J. Inorg. Chem. 1996, 36, 2242

(16) Almenningen, A.; Bastiansen, O.; Fernholt, L.; Cyvin, B. N.; Cyvin, S. J.; Samdal, S. J. Mol. Struct. 1985, 128, 59 .

(17) (a) Karpfen, A.; Choi, C. H.; Kertesz, M. J. Phys. Chem. A 1997, 101, 7426. (b) Choi, C. H.; Kertesz, M.; Karpfen, A. Chem. Phys. Lett. 1997, 276, 266

(18) Rubio, M.; Merchan, M.; Orti, E. Theor. Chim. Acta 1995, 91, 17.

(19) Tsuzuki, S.; Tanabe, K. J. Phys. Chem. 1991, 95, 139.

(20) The $C_{1}$-symmetric molecule 4-(o-tolyl)pyridine distorts about the inter-ring $\mathrm{C}-\mathrm{C}$ bond in order to reduce steric repusions between the methyl group and the closest pyridyl proton. The $C_{2}$-symmetric molecules 4-(2,6dimethylphenyl)pyridine and 4-phenylpyridine cannot do this.

(21) This was determined by projecting the nuclei along the norma coordinates of the two imaginary frequencies determined by the frequency calculations. The molecular and electronic structure viewing program MOLDEN was used.

(22) Head-Gordon. M.; Pople, J. A. J. Phys. Chem. 1993, 97, 1147.

(23) (a) Brock, C. P. J. Res. Natl. Inst. Stand. Technol. 1996, 101, 321, and references therein. (b) Brock, C. P.; Minton, R. P. J. Am. Chem. Soc 1989, 111, 4586, and references therein.

(24) Molecular orbitals for the SOMOs of these anions in their groundstate geometries were generated by the SPARTAN electronic structure calculation package: SPARTAN, version 4.0; Wavefunction, Inc.: 18401 Von Karman Ave, No. 370, Irvine, CA 92715, 1995. Using SPARTAN, single-point energy calculations were done with the appropriate UHF/6$31 \mathrm{G}(\mathrm{d})$ geometries determined from Gaussian 94 geometry optimization calculations. The appropriate molecular orbitals were then generated from these single-point energy calculations.

(25) Atkins, P. W. Molecular Quantum Mechanics; Oxford University Press: New York, 1988; p 285.

(26) Maruszewski, K.; Bajdor, K.; Strommen, D. P.; Kincaid, J. R. J Phys. Chem. 1995, 99, 6286, and references therein.

(27) The "structured" emission spectra correspond to data obtained on the bipyridyl complexes in a glass matrix, e.g., 2-MeTHF. It is possible that coupling to low-frequency modes might be discerned in highly resolved spectra obtainable from low-temperature single-crystal measurements. See, for example: Yersin, H.; Humbs, W.; Strasser, J. Top. Curr. Chem. 1997, 191,153 , and references therein.

(28) Miller, J. R.; Paulson, B. P.; Bal, R.; Closs, G. L. J. Phys. Chem. 1995, 99, 6923.

(29) Helms, A.; Heiler, D.; McLendon, G. L. J. Am. Chem. Soc. 1991, 113,4325

(30) Damrauer, N. H.; Cerullo, G.; Yeh, A.; Boussie, T. R.; Shank, C. V.; McCusker, J. K. Science 1997, 275, 54.

(31) Molecular orbitals for the SOMOs of these anions in their FranckCondon-state geometries were generated by the SPARTAN electronic structure calculation package: SPARTAN, version 4.0; Wavefunction, Inc.: 18401 Von Karman Ave, No. 370, Irvine, CA 92715, 1995. Using SPARTAN, single-point energy calculations were done with the appropriate MP2/6-31G(d) geometry of the corresponding neutral determined from Gaussian 94 geometry optimization calculations. The appropriate molecular orbitals were then generated from these single-point energy calculations

(32) Both the dpb and dotb systems will also exhibit an evolution in the extent of delocalization, evident from a comparison of Figure 6 with Figure 4. However, the effect should be most pronounced in the case of dmesb. 